\title{
Self-adaptive control system for additive manufacturing using double electrode micro plasma arc welding
}

\section{Nan Li}

Lanzhou University of Technology

Ding Fan ( $\nabla$ fand@lut.cn)

Lanzhou University of Technology

Jiankang Huang

Lanzhou University of Technology https://orcid.org/0000-0002-1257-8622

\section{Shurong Yu}

Lanzhou University of Technology

\section{Wen Yuan}

Lanzhou University of Technology

\section{Miaomiao Han}

Lanzhou University of Technology

\section{Original Article}

Keywords: Double electrode microplasma arc welding, Additive manufacturing, Wire feed rate, Torch stand-off distance, Self-adaptive adjustment

Posted Date: January 14th, 2021

DOl: https://doi.org/10.21203/rs.3.rs-19466/v2

License: (c) (i) This work is licensed under a Creative Commons Attribution 4.0 International License. Read Full License

Version of Record: A version of this preprint was published at Chinese Journal of Mechanical Engineering on June 9th, 2021. See the published version at https://doi.org/10.1186/s10033-021-00581-4. 


\title{
Self-adaptive control system for additive manufacturing using double electrode micro plasma arc welding
}

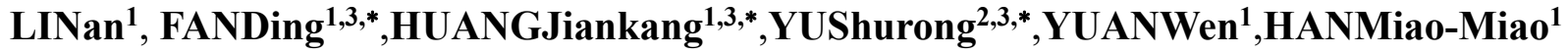 \\ 1. School of Materials Science and Engineering, Lanzhou University of Technology, Lanzhou 730050, China \\ 2.School of Mechanical and Electrical Engineering, Lanzhou University of Technology, Lanzhou 730050, China \\ 3.State Key Laboratory of Advanced Processing andRecycling of Non-ferrous Metals, Lanzhou University of Technology,Lanzhou 730050, \\ China
}

\begin{abstract}
Wire arc additive manufacturing (WAAM) has been investigated to deposit large-scale metal parts due to its high deposition efficiency and low material cost. However, in the process of automatically manufacturing the high-quality metal parts by WAAM, several problems about the heat build-up, the deposit-path optimization, and the stability of the process parameters need to be well addressed. To overcome these issues, a new WAAM method based on the double electrode micro plasma arc welding (DE-MPAW) was designed. The circuit principles of different metal-transfer models in the DE-MPAW deposition process were analyzed theoretically. The effects between the parameters, wire feed rate and torch stand-off distance, in the process of WAAM were investigated experimentally. In addition, a real-time DE-MPAW control system was developed to optimize and stabilize the deposition process by self-adaptively changing the wire feed rate and torch stand-off distance. Finally, a series of tests were performed to evaluate the control system's performance. The results show that the capability against interferences in the process of WAAM has been enhanced by this self-adaptive adjustment system. Further, the deposition paths about the metal part's layer heights in WAAM are simplified. Finally, the appearance of the WAAM-deposited metal layers is also improved with the use of the control system.
\end{abstract}

Keywords: Double electrode microplasma arc welding, Additive manufacturing, Wire feed rate, Torch stand-off distance, Self-adaptive adjustment

\section{Introduction}

Additive manufacturing (AM) has gotten wide publicity in the aerospace, medical, and architecture fields as it allows the unlimited design for complex parts and the automated build process at low costs[1]. As one type of technologies in AM, wire arc additive manufacturing (WAAM) is popular with the fabrication of large metal components because of its potential for lowering material and equipment costs, improving the deposition rate, and producing metal parts with a theoretically unlimited build

* Corresponding author:

FANDing,Email: fand@lut.cn;

HUANG Jiankang,Email: sr2810@163.con;

YU shurong, Email: yushur1991@163.com.

This work was funded by National Natural Science Foundation of China (No.51665034) volume[2]. In addition, a wide variety of metal parts of materials ranging from steel and aluminum to titanium has been successfully deposited using this process, such as steel wind tunnel models and cones, aluminum wing ribs, and Ti-6Al-4V spars[3].

WAAM is mainly divided into three techniques by the type of welding processes that include gas metal arc welding (GMAW), gas tungsten arc welding (GTAW), and plasma arc welding (PAW)[4]. In GMAW-based WAAM, the wire is used as an electrode to produce an arc on the substrate, and the wire is filled into the melt pool through the arc from above[5]. However, the excessive heat input, the metal spatter, and the arc wandering are three unavoidable issues in GMAW-based WAAM deposition process, which adversely affects the size precision and quality of the thus-deposited parts[6]. To address these issues, many ongoing researches focus on temperature control techniques. But temperature variations are sensitive to the formation of the internal grain structure and the degree of plastic/elastic deformation. Therefore, the 
temperature control techniques are not suitable to improve the heat accumulation in GMAW-based WAAM deposition process, especially for depositing complex and large-sized metal parts. Yang et al.[7], analyzed the heat transfer behavior of GMAW-based WAAM by using an infrared camera system that needs the accurate calibration test. The results showed that increasing the cooling time of inter-layers did not effectively improve the accumulation phenomenon of heat in depositing metal parts but decrease the parts-making efficiency in some degree.

In GTAW-based WAAM, an electric arc is produce from the tungsten electrode to the substrate, and the wire is filled into the melt pool through the arc from the side[8]. This method can effectively avoid the arc wonder and the metal spatter and decrease the heat accumulation presented in GMAW-based WAAM deposition process. Furthermore, the arc formed during PAW is smaller than that produced during GTAW, which results in a narrower heat-affected zone and higher arc energy density. PAW-based WAAM processes are better than GTAW-based WAAM for depositing metal parts[9]. Compared with PAW, the current in the micro plasma arc welding (MPAW) can be adjusted to range from $0.01 \mathrm{~A}$ to $50 \mathrm{~A}$ to get narrower heat-affected zone and lower thermal build-up. Therefore, the micro plasma arc welding (MPAW)-based WAAM process had been introduced as a economic and energy-saving alternative for fabricating small and medium-sized metal parts as well as repairing high-value components[10].

Except for the selection of arc welding methods, several parts of the WAAM process have also been looked into by lots of researchers, including thermal build-up[11-12], automated process planning[13-14], and online process control[15]. Wu et al.[16], probed into the effects of thermal build-up on the deposited layers as well as the metal transfer behavior in depositing of Ti-6Al-4V parts by GTAW-based WAAM. The results showed that the surface oxidation of the interlayer as well as its temperature and geometry varied along the depositing direction, resulting in variations of the metal-transfer behavior. Bai et al.[17], designed a 3D numerical model to analyze the flow of the metal pool and heat transfer behaviors during the multilayer depositing process using PAW-based WAAM. They found that, as the number of the deposit layers increasing, the geometry of the metal pool changes, in which its width increases, while the height decreases.

For the automated process planning, Kumar et al.[18], developed a raster-based and perimeter-based tool path generation method for performing $\mathrm{AM}$, in which the software MATLAB was used for algorithm implementation and the optimization of the tool path. Ding et al.[19], proposed a method named medial axis transformation (MAT) to provide the tool-paths for WAAM. Compared with the conventional contour patterns for depositing thin-walled parts, the deposited metal parts used MAT-based path planning strategy get the better performance and gap-free cross-sections.Venturini et al.[20], developed a feature-based computer-aided manufacturing software for depositing thin-walled components to improve its geometrical accuracy to ensure the required machining errors for the finishing operations.

For online process control techniques, Xiong et al.[21], designed a parameter adjusting system for GMAW-based WAAM to adjust the deposition rate to ensure that the layer heights of the deposited part remained constant. In the deposition process, a passive vision sensor system was used to test the distance from the nozzle to the top of the deposited parts. Dong et al.[22], put forward a method using Gaussian process regression and Bayesian optimization algorithm to model the continuous GTAW process and predict the geometry of the metal pool. In order to resolve the issue of poor corner accuracy during the fabrication of complex-shaped components by CMT-based WAAM, Li et al.[23], divided the depositing path into a few segments based on the features of the deposited parts and introduced a process control program by matching the travel speed with the depositing rate in each segment.

Above all, recent researches on WAAM have mainly focused on characterizing and evaluating the WAAM methods are available or not for depositing metal parts. Meanwhile, several researchers have respectively investigated online process control, automated process planning, and thermal build-up control[24]. However, in order to enhance the stability of the deposition process, geometric accuracy, and quality of the deposited parts, the development of WAAM techniques for metal parts, in particular, for fabricating large-scale structural parts and complex-shaped metal components, requires the integration of thermal build-up control, process planning, and online process control[25].

Fortunately, the micro plasma arc has several advantages for the heat producer of WAAM, such as high arc stiffness and energy density, small heat-affected zone, and a wide adjustment range of the power parameter[26]. In addition, the alternative use of non-transferred arc and transferred arc can improve the arc turn-on/offfrequency inthe process of MPAW-based WAAM.

Given these merits of MPAW and double-electrode arc welding (DE-AW) [27-28], in this study, we developed an innovative WAAM process that uses double electrode 
micro plasma arc welding (DE-MPAW) to ensure greater control over thermal build-up andthe process stability. Meanwhile, a control platform based on an xPC Target system was used to optimize and control the DE-MPAW-based WAAM deposition process. Furthermore, a control strategy was designed to simplify the process of planning the deposition paths on the deposited layers. The system was successfully used to deposit metal parts on complex-shaped substrates by varying the wire feed rate and torch stand-off distance real-time. Finally, several experiments were carried on to evaluate the performance of the control system.

\section{Materials and methods}

The setup of the proposed DE-MPAW control system is presented in Figure1. It includes a LHM-50 welding source, a WF-007b wire feeder, an AMR-300 resistance device, a CP-80 filming system, a 3-axes motion system and a XPC Target system. The xPC system is assembled by a host PC, a target PC, PCL-812PG and PCL-728 data acquisition devices, and Hall current-voltage sensors. CML-50 is a motion control device connected with the xPC system to independently control the $\mathrm{Z}$ axe of the 3-axes motion system.

As depicted in Figure 1(a), the LHM-50 welding power source, which had a direct current range of $0.08-50 \mathrm{~A}$, is applied to make a constricted arc with negative polarity. The power source, electrode, and substrate form the main current loop. Meanwhile, the AMR-300 in series with the wire is added into the main circuit loop as a bypass part to control the heat flowing into the substrate. The data corresponding to the total and bypass currents are collected by the Hall sensors, while the data corresponding to the total and bypass voltages are collected by the voltage transmitter. Furthermore, based on the A/D conversion functionality of the PCL-812PG card, the analog data are individually converted into the digital data to be used as the input for the xPC Target system. The program of the control system can be designed in Matlab/Simulink on the host PC. This program needs be loaded into the target PC via the TCP/IP communication protocol to individually control WF-007b and CML-50 in order to ensure the appropriate wire feed rate and torch stand-off distance. Meanwhile, the program can also be revised and modified real-time in Matlab/Simulink. The program outputs the analog signal corresponding to the wire feed rate from the PCL-728 multifunction data acquisition card to the WF-007b wire feeder to change the wire feed rate in real time.
To control the arc length, the welding torch and the wire added by the WF-007b feeder, are fixed together to the 3D-motion platform's z-axis. The application outputs ON-OFF signals from the PCL-812PG multifunction data acquisition card to CML-50 to automatically make the $\mathrm{z}$-axis move up and down. Further, the substrate is clamped to the $x-y$ table of the 3D motion platform, which is controlled with a PC with a motion-controlling card to move the substrate along the $\mathrm{x}$ - and $\mathrm{y}$-axes.

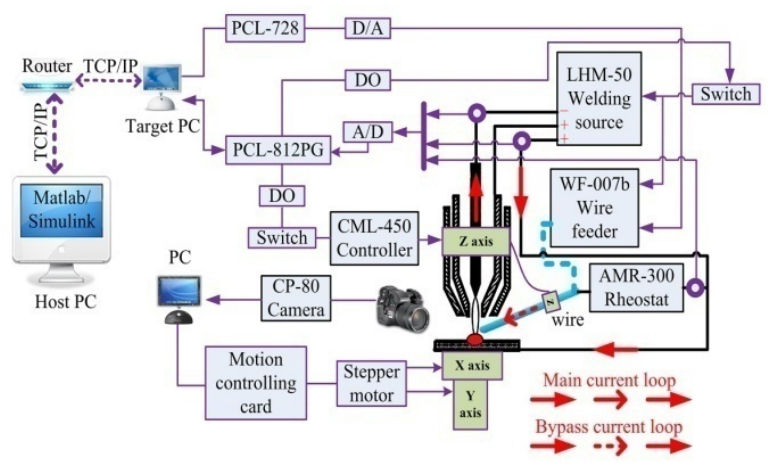

(a) Schematic of experimental setup

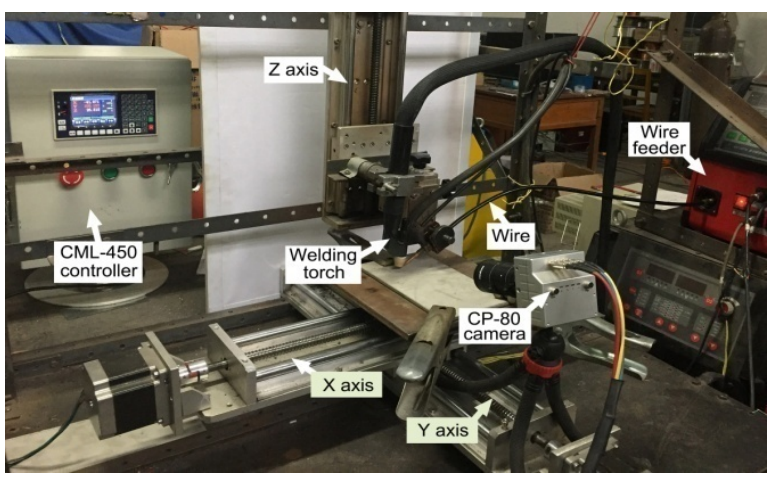

(b) Photograph of setup

Figure1 Experimental setup of DE-MPAW control system

\section{Self-adaptive DE-MPAW control system 3.1 Circuit principle of DE-MPAW control system}

Figure 2 shows the principle of the DE-MPAW system during the deposition process. The DE-MPAW system can be regarded as a circuit whose components are the micro plasma arc, substrate, deposited layers, feed wire, and rheostat. The micro plasma arc can be considered a special resistor $\left(R_{1}\right)$ whose current and voltage exhibit a nonlinear relationship and whose voltage is determined by the current and torch stand-off distance $(H)$. The substrate and deposited layers can together be considered as another resistor $\left(R_{2}\right)$. Finally, $R_{3}$ and $R_{4}$ are the wire and rheostat, respectively. 


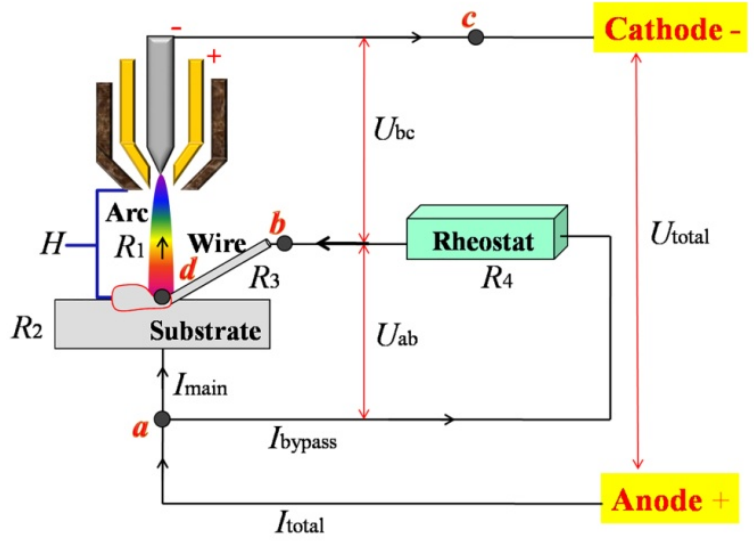

Figure2 Relationship between voltage and current during DE-MPAW process

The main current $\left(I_{\text {main }}\right)$ is the current flowing through the deposited layers and substrate. The bypass current ( $I_{\text {bypass }}$ ) is the current flowing through the wire and rheostat. $I_{\text {total }}$ is the total current, which can be set in the welding source panel of the micro plasma arc.

The total voltage $\left(U_{\text {total }}\right)$ is the voltage between the anode (point a) and cathode (point c), $U_{\text {arc }}$ refers to the voltage of the micro plasma arc, and the bypass voltage ( $\left.U_{\text {bypass }}\right)$ is the voltage between the anode and the left end of the wire (point d). Finally, $U_{\mathrm{ab}}$ represents the voltage of the rheostat. $I_{\text {total }}, I_{\text {bypass }}, U_{\text {total }}$, and $U_{\text {ab }}$ can be measured readily using the voltage and current data acquisition system. Because the bypass voltage is difficult to measure, $U_{\mathrm{ab}}$ can be approximated as the bypass voltage in the
DE-MPAW system. The relationships between these parameters are as follows:

$$
\begin{gathered}
I_{\text {main }}=I_{\text {total }}-I_{\text {bypass }}, \\
U_{\text {bypass }}=I_{\text {bypass }}\left(R_{3}+R_{4}\right), \\
U_{\text {bypass }} \approx U_{\text {ab }}=I_{\text {bypass }} R_{4},
\end{gathered}
$$

\subsection{Effects of wire feed rate and torch stand-off distance}

The maximum wire feed rate plays a key role in the efficient deposition of metal parts. In order to measure the maximum wire feed rate corresponding to the different total currents and torch stand-off distances, single-pass weld deposition experiments were performed. Using the CP-80 camera, the maximum rate was determined by recording the wire feed rate of the wire feeder when the wire was about to extend outside the melt pool. The current and voltage data were collected using the xPC Target system shown in Figure1. A specimen of the austenitic stainless steel 304 with dimensions of $200 \mathrm{~mm} \times 100 \mathrm{~mm} \times 3 \mathrm{~mm}$ was used as the substrate. The deposited material was a welding wire of the stainless steel $304 \mathrm{~L}$ with a diameter of $0.8 \mathrm{~mm}$. The chemical compositions of the substrate and deposited wire are shown in Table 1.

Table1 Chemical compositions(wt $\%$ ) of substrate and deposited material

\begin{tabular}{lllllllll}
\hline Elements & $\mathrm{C}$ & $\mathrm{Si}$ & $\mathrm{Mn}$ & $\mathrm{P}$ & $\mathrm{S}$ & $\mathrm{Cr}$ & $\mathrm{Ni}$ & $\mathrm{Fe}$ \\
\hline Substrate & 0.07 & 0.47 & 1.12 & 0.02 & 0.03 & 18.50 & 8.25 & Bal. \\
Deposited material & 0.06 & 0.30 & 2.00 & 0.03 & 0.02 & 19.00 & 11.00 & Bal. \\
\hline
\end{tabular}

The various processing parameters and their ranges used in this study are presented in Table 2 . The values of the travel speed $(v)$, plasma orifice gas flow rate $\left(L_{1}\right)$, shield gas flow rate $\left(L_{2}\right)$, and wire feeding angle $(\theta)$ were kept constant. The total current was varied from 25 to $50 \mathrm{~A}$ in intervals of $5 \mathrm{~A}$, while the torch stand-off distance ranged from 5 to $8 \mathrm{~mm}$ in intervals of $1 \mathrm{~mm}$. The wire feed rate $\left(V_{\mathrm{s}}\right)$, and total voltage $\left(U_{\text {total }}\right)$ were the parameters to be measured. The welding source power $(P)$ was the parameter to be calculated. A total of 24 experiments were performed, as shown in Table 3 .

Table2 Processing parameters and their ranges

\begin{tabular}{lll}
\hline Parameter & Unit & Values \\
\hline Total current $\left(I_{\text {total }}\right)$ & A & $25,30,35,40,45,50$ \\
Travel speed $(v)$ & $\mathrm{mm} / \mathrm{min}$ & 80 \\
Torch stand-off distance $(H)$ & $\mathrm{mm}$ & $5,6,7,8$ \\
Plasma orifices gas flow rate $\left(L_{1}\right)$ & $1 / \mathrm{min}$ & 1.0
\end{tabular}


Shield gas flow rate $\left(L_{2}\right)$

Wire feeding angle $(\theta)$

Weld source power $(P)$

Total voltage $\left(U_{\text {total }}\right)$

Wire feed rate $\left(V_{\mathrm{s}}\right)$

$\begin{array}{ll}1 / \mathrm{min} & 10.0 \\ \text { Degree } & 60 \\ \mathrm{~W} & \text { to be calculated } \\ \mathrm{V} & \text { to be measured } \\ \mathrm{cm} / \mathrm{min} & \text { to be measured }\end{array}$

Table3 Sets of processing parameters and their respective outcomes

\begin{tabular}{|c|c|c|c|c|c|}
\hline $\begin{array}{l}\text { Experiment } \\
\text { ID }\end{array}$ & $\begin{array}{l}H \\
(\mathrm{~mm})\end{array}$ & $\begin{array}{l}I_{\text {total }} \\
\text { (A) }\end{array}$ & $\begin{array}{l}U_{\text {total }} \\
(\mathrm{V})\end{array}$ & $\begin{array}{l}P \\
(\mathrm{~W})\end{array}$ & $\begin{array}{l}V_{\mathrm{s}} \\
(\mathrm{cm} / \mathrm{min})\end{array}$ \\
\hline 1 & 5 & 25 & 21.34 & 526.03 & 117 \\
\hline 2 & 5 & 30 & 22.22 & 663.04 & 139 \\
\hline 3 & 5 & 35 & 23.13 & 806.08 & 158 \\
\hline 4 & 5 & 40 & 23.94 & 960.47 & 174 \\
\hline 5 & 5 & 45 & 24.72 & 1119.07 & 189 \\
\hline 6 & 5 & 50 & 24.71 & 1252.30 & 206 \\
\hline 7 & 6 & 25 & 22.49 & 559.32 & 128 \\
\hline 8 & 6 & 30 & 23.3 & 696.20 & 147 \\
\hline 9 & 6 & 35 & 24.49 & 851.52 & 168 \\
\hline 10 & 6 & 40 & 24.47 & 976.35 & 200 \\
\hline 11 & 6 & 45 & 25.4 & 1145.54 & 220 \\
\hline 12 & 6 & 50 & 25.53 & 1289.01 & 240 \\
\hline 13 & 7 & 25 & 23.02 & 568.36 & 135 \\
\hline 14 & 7 & 30 & 23.97 & 711.66 & 154 \\
\hline 15 & 7 & 35 & 24.53 & 855.36 & 176 \\
\hline 16 & 7 & 40 & 25.00 & 998.00 & 206 \\
\hline 17 & 7 & 45 & 25.70 & 1160.61 & 227 \\
\hline 18 & 7 & 50 & 26.21 & 1335.66 & 246 \\
\hline 19 & 8 & 25 & 23.89 & 590.32 & 123 \\
\hline 20 & 8 & 30 & 24.89 & 727.29 & 138 \\
\hline 21 & 8 & 35 & 25.64 & 895.86 & 157 \\
\hline 22 & 8 & 40 & 26.38 & 1055.50 & 179 \\
\hline 23 & 8 & 45 & 26.27 & 1188.70 & 199 \\
\hline 24 & 8 & 50 & 26.63 & 1343.20 & 231 \\
\hline
\end{tabular}

The metal-transfer models for various total currents and torch stand-off distances when the wire feed rate is the highest is shown in Figure3. It is clear that, irrespective of the total current and torch stand-off distance, the bridging-transfer model corresponds to the highest wire feed rate.The top two pictures show that,when the total current is kept constant, the wire feed rate increases with the torch stand-off distance. The bottom two pictures show that,when the torch stand-off distance is kept constant, the wire feed rate increases with the total current. Finally, the images in the left and right columns show that the effect of the total current on the wire feed rate is more pronounced 
than that of the torch stand-off distance.

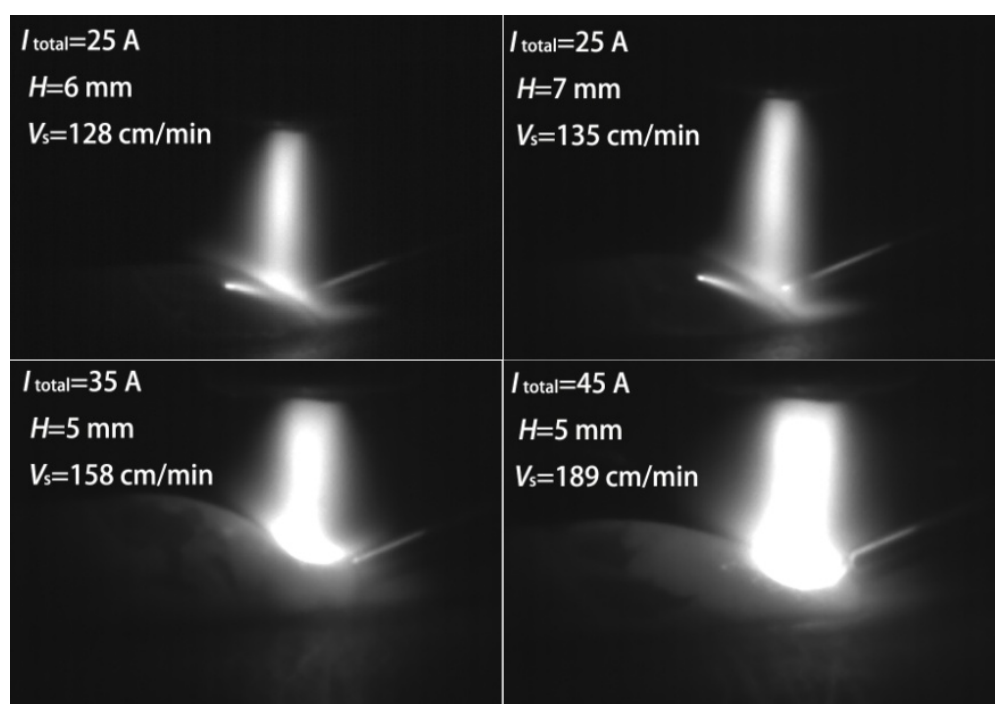

Figure3 Metal-transfer modes corresponding to maximum wire feed rate

The relationship between the total voltage and current depicted in Figure 4. for torch stand-off distances of $5,6,7$, and $8 \mathrm{~mm}$ are

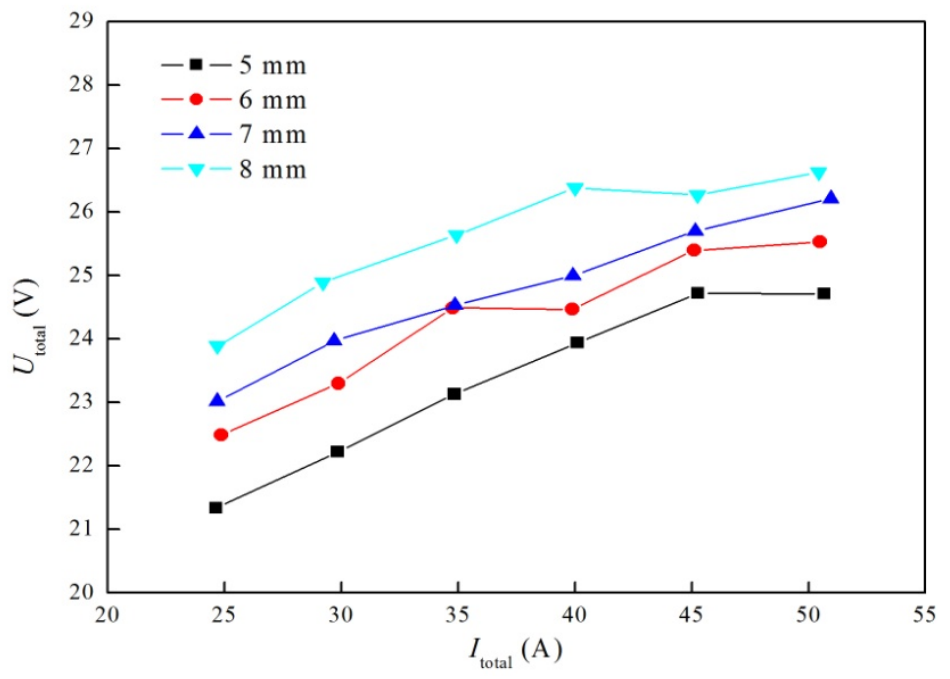

Figure4 Relationships between total voltage and current for different torch stand-off distances.

The total voltage increases with the current and torch stand-off distance, and these two parameters together determine the total voltage during the DE-MPAW deposition process. Based on the synergistic effects of the total current and torch stand-off distance on the total voltage, the following relationship for the total voltage is obtained:

$$
\begin{gathered}
U_{\text {total }}=\varepsilon_{1} H+\varepsilon_{2} I_{\text {total }}+\varepsilon_{3} H \cdot I_{\text {total }}+\varepsilon_{4}, \\
\boldsymbol{U}_{\text {total }}=\left[U_{\mathrm{ij}}\right]_{4 \times 6}, \boldsymbol{H}=\left[H_{\mathrm{ij}}\right]_{4 \times 6},
\end{gathered}
$$

$$
\boldsymbol{I}_{\text {total }}=\left[I_{\mathrm{ij}}\right]_{4 \times 6}, \boldsymbol{H} \cdot \boldsymbol{I}_{\text {total }}=\left[H_{\mathrm{ij}} \cdot I_{\mathrm{ij}}\right]_{4 \times 6},
$$

where index values of $i=1,2,3$, and 4 correspond to torch stand-off distances of 5,6,7, and $8 \mathrm{~mm}$, respectively. Further, index values of $\mathrm{j}=1,2,3,4,5,6$ represent total currents of $25,30,35,40,45$, and 50A, respectively.

Based on Eq. (4) and the parameter matrices given in Eq. (5) and Eq. (6), the following results can be obtained by linear fitting the total voltage data: 


$$
\begin{aligned}
& {\left[\begin{array}{cccc}
1 & 0 & 37.5 & 0 \\
0 & 1 & 6.5 & 0 \\
6.5 & 0 & 0 & 1 \\
0 & 37.5 & 0 & 1
\end{array}\right] \times\left[\begin{array}{c}
\varepsilon_{1} \\
\varepsilon_{2} \\
\varepsilon_{3} \\
\varepsilon_{4}
\end{array}\right]=\left[\begin{array}{c}
0.73 \\
0.12 \\
19.82 \\
19.85
\end{array}\right],} \\
& \varepsilon_{1}>0.87, \varepsilon_{2}>0.1382, \varepsilon_{3}<0, \varepsilon_{4}>0,
\end{aligned}
$$

Furthermore, five sets of the coefficient matrix $(\varepsilon)$ could be calculated by Eq. (7) and Eq. (8), as shown below:

$$
\boldsymbol{\varepsilon}^{1}=\left[\begin{array}{c}
1.4 \\
0.236 \\
-0.018 \\
11.0175
\end{array}\right], \boldsymbol{\varepsilon}^{2}=\left[\begin{array}{c}
1.8 \\
0.305 \\
-0.029 \\
8.4175
\end{array}\right], \boldsymbol{\varepsilon}^{3}=\left[\begin{array}{c}
2.1 \\
0.357 \\
-0.037 \\
6.4675
\end{array}\right],
$$

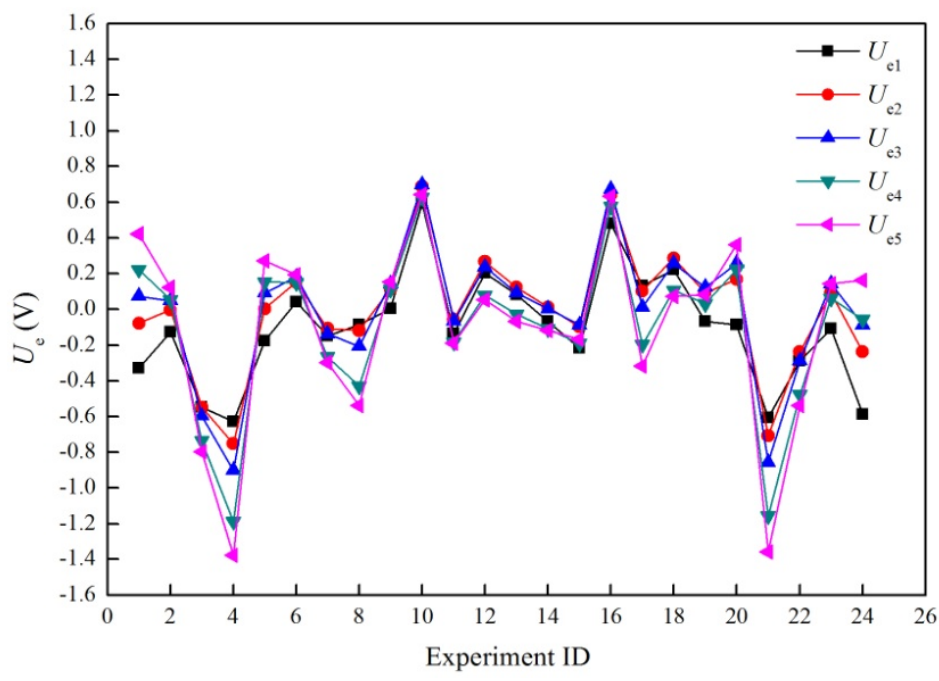

Figure5 Error between experimentally determined and calculated total voltage values corresponding to different coefficient matrices.

Here, $\boldsymbol{E}_{\mathbf{m}}$ is the mean value of $U_{\mathrm{e}}$ corresponding to the different coefficient matrices, $\boldsymbol{\varepsilon}$, and $\boldsymbol{E}_{\mathbf{v}}$ is the variance of $U_{\mathrm{e}}$. Their values are given below:

$$
\begin{gathered}
\boldsymbol{E}_{\mathrm{m}}=\left[\begin{array}{lllll}
-0.102 & -0.008 & -0.008 & -0.110 & -0.102
\end{array}\right], \\
\boldsymbol{E}_{\mathrm{v}}=\left[\begin{array}{llllll}
0.304 & 0.333 & 0.371 & 0.434 & 0.513
\end{array}\right]
\end{gathered}
$$

The value of $\boldsymbol{E}_{\mathbf{m}}$ was the lowest (-0.008) for the coefficient matrices $\varepsilon^{2}$ and $\varepsilon^{3}$. Further, $\boldsymbol{E}_{\mathbf{v}}$ was 0.333 for $\varepsilon^{2}$ and less than that for $\varepsilon^{3}$. Consequently, the total voltage calculated by Eq. (4) and the coefficient matrix $\varepsilon^{2}$ was in keeping with the experimental data, and the equation for the total voltage could be written as

$U_{\text {total }}=1.8 H+0.305 I_{\text {total }}-0.029 H \cdot I_{\text {total }}+8.4175$,

The relationships between the calculated total voltage

$$
\boldsymbol{\varepsilon}^{4}=\left[\begin{array}{c}
2.5 \\
0.426 \\
-0.0472 \\
3.8675
\end{array}\right], \boldsymbol{\varepsilon}^{5}=\left[\begin{array}{c}
2.9 \\
0.496 \\
-0.058 \\
1.2675
\end{array}\right],
$$

The total voltage was determined by substituting the coefficient matrices $\varepsilon^{1}, \varepsilon^{2}, \varepsilon^{3}, \varepsilon^{4}$,and $\varepsilon^{5}$ in Eq. (4).The error $\left(U_{\mathrm{e}}\right)$ between the experimentally determined and calculated total voltage values is shown in Figure 5. and total current for the different torch stand-off distances are shown in Figure 6.

Figure 7 shows the relationships betweenthe torch stand-off distance, total current, and wire feed rate. With an increase in the total current from 25 to $50 \mathrm{~A}$ in intervals of $5 \mathrm{~A}$, the curves for the relationship between the torch stand-off distance and wire feed rate changed dramatically. Thus, it can be concluded that the wire feed rate was sensitive to the torch stand-off distance at lower total currents.

In addition, for torch stand-off distances of 5, 6, 7, and $8 \mathrm{~mm}$, the wire feed rate increased with the total current. Therefore, the torch stand-off distance and total current both affect the wire feed rate. 


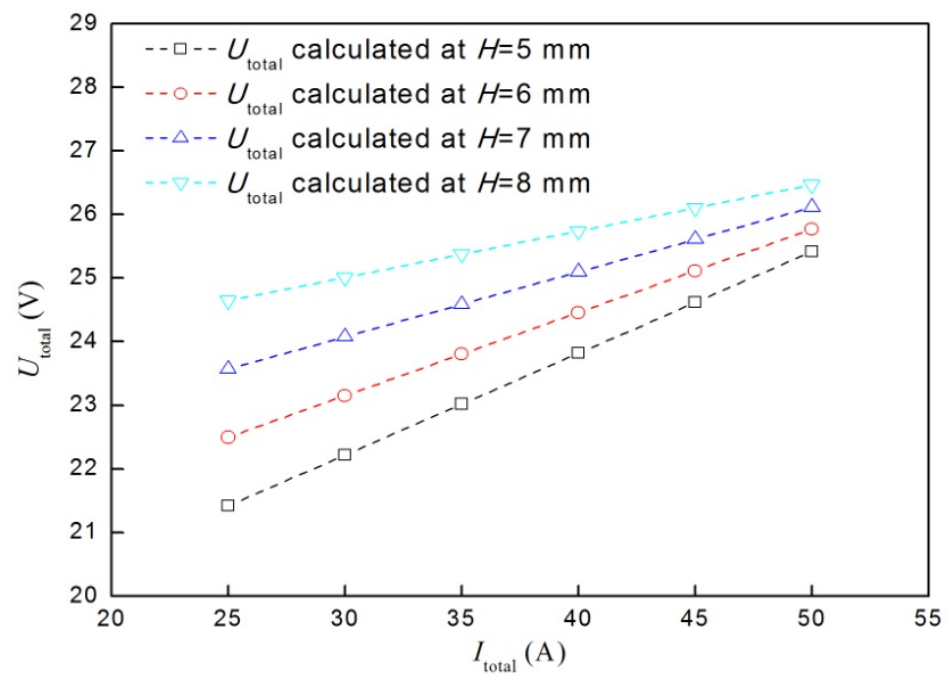

Figure6 Relationships between calculated total voltage and total current for different torch stand-off distances

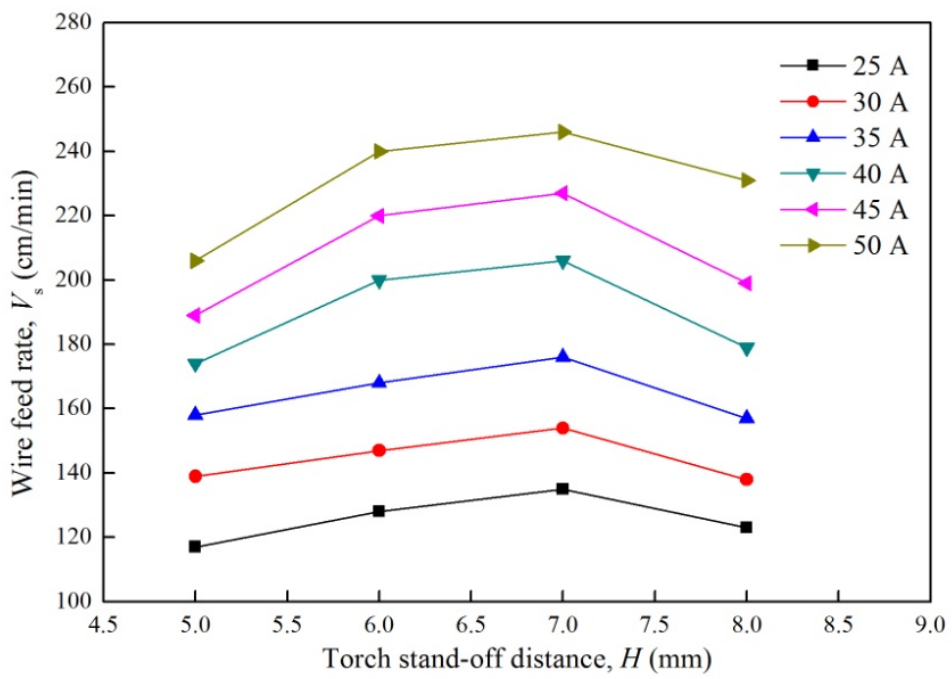

Figure7 Relationships between wire feed rate and torch stand-off distance for different total currents

Furthermore, the total voltage is also determined by the torch stand-off distance and total current, as shown in Eq. (12). Besides, the wire feed rate is related to the amount of thermal energy available, and the weld source power is given by

$$
P=U_{\text {total }} \cdot I_{\text {total }} \text {, }
$$

Thus, the wire feed rate is also related to the weld source power. The effect of the weld source power on the wire feed rate is shown in Figure 8.

The experimental data for the wire feed rate could be fitted using following linear function:

$$
V_{\mathrm{s}}=0.14 P+46.02 \text {, }
$$




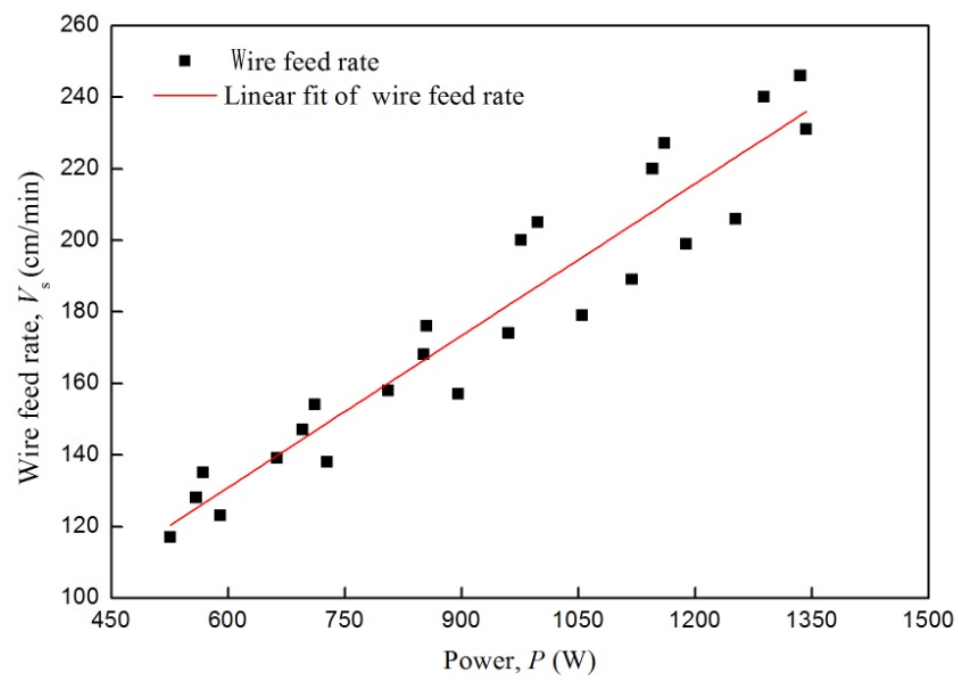

Figure8 Relationship between wire feed rate and weld source power.

\subsection{Effects of bypass voltage on metal-transfer model}

Phenomena such as heat accumulation, mismatch in the wire feed rate, and arc wander during the WAAM deposition process lead to dynamic changes in the relative positions of the wire end and weld pool. Owing to these changes, the metal-transfer model switches between the bridge-transfer model and the droplet-transfer model. As a result, the circuit for the deposition process also switches dynamically between those corresponding to these two metal-transfer models.

When the wire end remains in contact with the weld pool through a liquid bridge during the deposition process, the valid metal-transfer model is the bridging-transfer model. The DE-MPAW circuit in the case of the bridging-transfer model is shown in Figure 9.

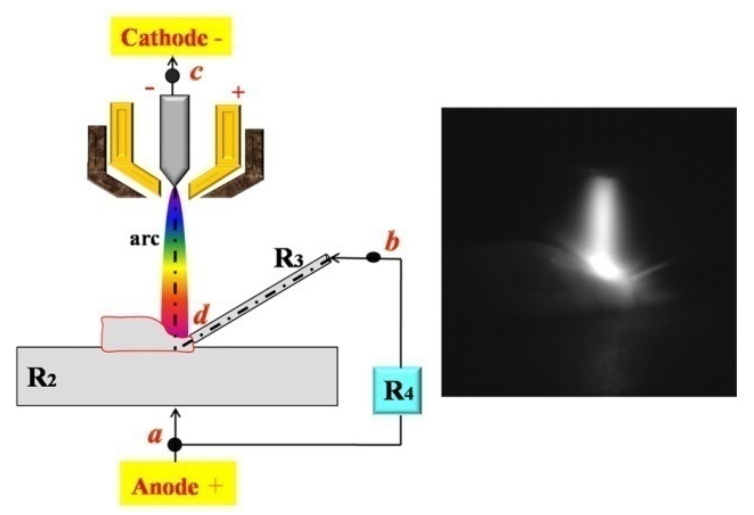

Figure9 Circuit for DE-MPAW system in case of bridging-transfer model.

On the other hand, when the wire extends into the weld pool, the micro plasma arc can be approximated by a resistor in series with $R_{2}$. Meanwhile, $R_{2}$ is in parallel with
$R_{3}$ and $R_{4}$, which constitute a parallel circuit. The equations for the circuit corresponding to the bridging-transfer model can be assumed to be the following:

$$
\begin{gathered}
U_{\text {bypass }}^{1}=U_{\text {ad }}=U_{\mathrm{R}_{2}}, \\
I_{\text {bypass }}^{1}==\frac{U_{\text {bypass }}^{1}}{R_{3}+R_{4}},
\end{gathered}
$$

Where $U_{\text {bypass }}^{1}$ and $I_{\text {bypass }}^{1}$ are the bypass voltage and current, respectively, in the circuit, and $U_{\text {ad }}$ isthe voltage between the points' $a$ ' and ' $d$ '.

If the torch stand-off distance increases by $\Delta H$ in the bridging-transfer mode, the wire end will extend into the micro plasma arc during the DE-MPAW deposition process. In this case, the metal is transferred into the welding pool in the droplet-transfer model, which is represented by a different circuit.

The circuit for the droplet-transfer model is shown in Figure 10. The micro plasma arc corresponding to $\Delta H$ micro plasma arc of $\Delta H$ is added to the main part of the circuit in series with $R_{2}$. As a result, the components of the parallel circuit are now the micro plasma arc corresponding to $\Delta H, R_{2}, R_{3}$, and $R_{4}$. The equations for the circuit corresponding to the droplet-transfer model are as follows:

$$
\begin{gathered}
U_{\text {total }}^{2}=U_{\text {total }}^{1}+U_{\Delta \mathrm{H}}, \\
U_{\text {bypass }}^{2}=U_{\text {ad }}=U_{\mathrm{R}_{2}}+U_{\Delta \mathrm{H}}, \\
I_{\text {bypass }}^{2}=\frac{U_{\text {bypass }}^{2}}{R_{3}+R_{4}},
\end{gathered}
$$

where $U_{\text {total }}^{1}$ is the total voltage in the circuit under the 
bridging-transfer model; $U_{\text {total }}^{2}$ is the total voltage in the circuit corresponding to the droplet-transfer model when the torch stand-off distance increases by $\Delta H ; U_{\text {bypass }}^{2}$ and $I_{\text {bypass }}^{2}$ are the bypass voltage and current, respectively, in the circuit for the droplet-transfer modelwhen the torch stand-off distance increases by $\Delta H$; and $U_{\Delta \mathrm{H}}$ is the voltage drop of the micro plasma arc when the torch stand-off distance increases by $\Delta H$.

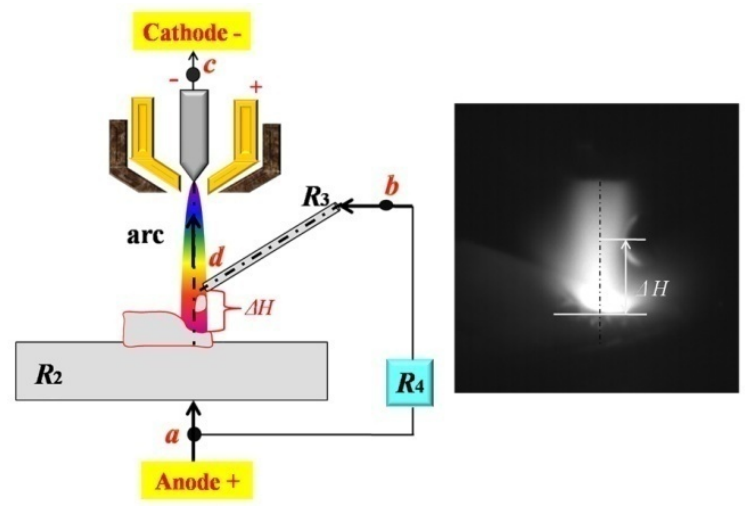

Figure10 Circuit of DE-MPAW system corresponding to droplet-transfer model

Consequently, based on the voltage drop of the arc $\left(U_{\Delta H}\right)$, the differences between the two circuits can be written as shown below:

$$
U_{\text {total }}^{2}>U_{\text {total }}^{1}, U_{\text {bypass }}^{2}>U_{\text {bypass }}^{1}, I_{\text {bypass }}^{2}>I_{\text {bypass }}^{1},
$$

In addition, if the wire feed rate decreases such that the wire end extends into the micro plasma arc, the circuit switches from the bridging-transfer circuit to the droplet-transfer circuit. In this case too, the micro plasma arc corresponding to $\Delta H$ is added to the main part of the circuit in series with $R_{2}$. The resistance of the wire, $\mathrm{R}_{3}$, is lower than that in the bridging-transfer model. However, the torch stand-off distance remains unchanged. Thus, the differences between these two circuits can be written as shown below:

$$
U_{\text {total }}^{3}=U_{\text {total }}^{1}, U_{\text {bypass }}^{3}>U_{\text {bypass }}^{1}, I_{\text {bypass }}^{3}>I_{\text {bypass }}^{1},
$$

Where $U_{\text {total }}^{3}, U_{\text {bypass }}^{3}$, and $I_{\text {bypass }}^{3}$ are the total voltage, bypass voltage, and current, respectively, in the circuit corresponding to the droplet-transfer model when the wire feed rate decreases.

From Eq. (20) and Eq. (21), it is clear that whether the micro plasma arc corresponding to $\Delta H$ is caused by the torch stand-off distance or wire feed rate, the values of $I_{\text {bypass }}$ and $U_{\text {bypass }}$ corresponding to the droplet-transfer model are larger than those in the bridging-transfer model. Therefore, both $I_{\text {bypass }}$ and $U_{\text {bypass }}$ can be used as indices to monitor the manner in which the metal is transferred into the welding pool.

\subsection{Self-adaptive control model}

The bridging-transfer model can track higher wire feed rates to improve deposition efficiency. We used $U_{\text {bypass }}$ as anindex to evaluate thetransfer of themetal into the weld pool. The torch stand-off distance and wire feed rate have a determining effect on the manner in which the deposition material is transferred into the weld pool during the DE-MPAW process. Thus, controlling the torch stand-off distance and wire feeding rate is one way of ensuring stable and high-efficiency DE-MPAW AM.

Based on Eq.(12) and Eq. (14) and the effects of the bypass voltage on the metal-transfer models, we developed a DE-MPAW control system that self-adaptively adjusts the wire feed rate and torch stand-off distance.

A schematic of DE-MPAW control system is shown in Figure 11. Parameters, $v, \theta, L_{1}$, and $L_{2}$ are constants, and their values are listed in Table 2 . Further, $I_{\text {total }}, H$, and $U_{\text {bypass, }}$ are the inputs of the control system while $H, V_{\mathrm{s}}$, and $U_{\text {bypass }}$ are the outputs.

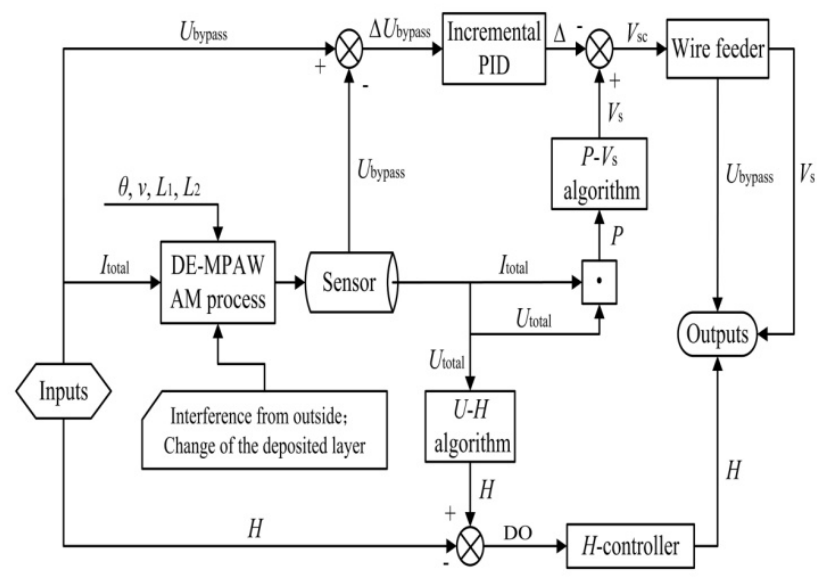

Figure11 Structure of proposed DE-MPAW control system

Input $U_{\text {bypass }}$ is the reference bypass voltage corresponding to the bridging-transfer model. Its value is determined by the initial values of $H$ and $I_{\text {total. }}$. Parameters $U_{\text {bypass, }} I_{\text {total }}$, and $U_{\text {total }}$ can be measured real-time during the DE-MPAW process using sensors. In the case of outside interference or changes in the deposited layer during the deposition process, an error, $\Delta U_{\text {bypass }}$, is inputted to the incremental PID controller, whose output is an increment, $\Delta$. Based on the measured signals, $I_{\text {total }}$ and $U_{\text {total, }}$, the power signal, $P$, output is given by Eq.(12). Using the $P-V_{\mathrm{s}}$ algorithm described in Eq.(13), the corresponding wire feed rate, $V_{\mathrm{s}}$, is determined. Simultaneously, the increment, $\Delta$, is used to adjust the 
wire feed rate, $V_{\mathrm{s}}$, and decrease the error, $\Delta U_{\text {bypass }}$. Consequently, the adjusted wire feed rate is passed as the output to the wire feeder using the wire feed signal, $V_{s c}$ which changes in real time through this self-adaptive adjustment process.

Meanwhile, based on the measured signal, $U_{\text {total, the }}$ torch stand-off distance, $H$, is outputted by the $U-H$ algorithm described in Eq. (12). Further, based on the self-adaptive adjustment range of $H$, the digital output (DO) signal is outputted to make the $H$-controller change the height of the welding torch real-time to stabilize $H$ over this range.

As shown in Figure 12, the self-adaptive DE-MPAW control system was implemented in the $\mathrm{xPC}$ Target real-time environment using the MATLAB/Simulink software platform. $H$ ranged from 5.8 to $6.2 \mathrm{~mm}$, and the initial value of $I_{\text {total }}$ was set to $35 \mathrm{~A}$. The reference bypass voltage corresponding to the bridging-transfer model was $1.92 \mathrm{~V}$.

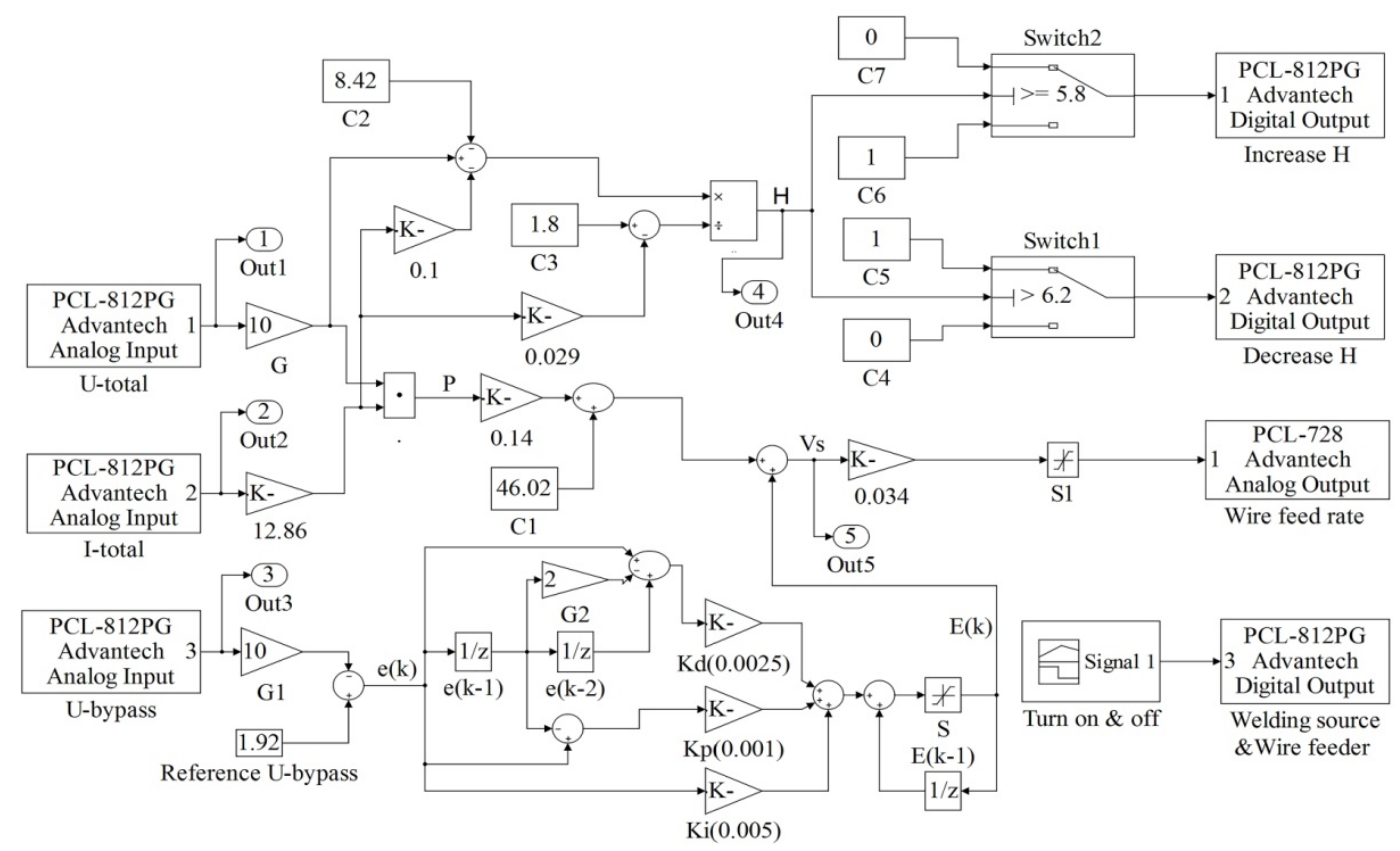

Figure12 Diagram of self-adaptive DE-MPAW control system

With respect to the self-adaptive adjustment of $H$, if $H$ is less than $5.8 \mathrm{~mm}$, switch 1 turns on, and a signal for increasing $H$ is sent by output end 1 of the PCL-812 card to the CML-50 controller. As a result, the welding torch is made to move up automatically in order to increase $H$. However, if $H$ is larger than $6.2 \mathrm{~mm}$, switch 2 turns on and a signal to decrease $H$ is sent by output end 2 of the PCL-812 card to the CML-50 controller. In this case, the

$$
E(\mathrm{k})=E(\mathrm{k}-1)+k_{\mathrm{i}} e(\mathrm{k})+k_{\mathrm{p}}[e(\mathrm{k})-e(\mathrm{k}-1)]+k_{\mathrm{d}}[e(\mathrm{k})-2 e(\mathrm{k}-1)+e(\mathrm{k}-2)],
$$

where $k_{\mathrm{p}}$ is the constant of proportionality and has a value of $0.001 ; k_{\mathrm{i}}$ is the constant of integration and has a value of 0.005 ; and $k_{\mathrm{d}}$ is the constant of differentiation and has a value of 0.0025 .

If the measured $U_{\text {bypass }}$ is large than the reference voltage, the increment $E(\mathrm{k})>0$, and it is outputted to the wire feeder to increase $V_{\mathrm{s}}$. However, if the measured $U_{\text {bypass }}$ is less than the reference value, $E(\mathrm{k})<0$, and the increment is outputted to the wire feeder to decrease $V_{\mathrm{s}}$. welding torch is controlled to move down automatically in order to decrease $H$.

For the self-adaptive adjustment of $V_{\mathrm{s}}, V_{\mathrm{s}}$ is outputted by the $P-V_{\mathrm{s}}$ algorithm program. Meanwhile, the error, $e(\mathrm{k})$, between the reference and measured values of $U_{\text {bypass }}$ is inputted to the incremental PID program, which outputs the increment, $E(\mathrm{k}) . E(\mathrm{k})$ is given by

Finally, if the measured $U_{\text {bypass }}$ is equal to the reference voltage, $E(\mathrm{k})=0$, and $V_{\mathrm{s}}$ remains unchanged.

\section{Evaluation of self-adaptive DE-MPAW control system}

Phenomena such as changes in the height of the deposited layer and overheating of the weld pool as well 
as cross-paths during the AM process adversely affect the final geometry and quality of the deposited parts. To evaluate the self-adaptive DE-MPAW control system, a series of tests were performed to verify the availability of the material to be deposited during the deposition process where in the height of deposition varied.

\subsection{Sloping-substratetest}

Two 304 austenitic stainless steel samples with dimensions of $200 \mathrm{~mm} \times 100 \mathrm{~mm} \times 3 \mathrm{~mm}$ were used to form a sloping substrate. The deposited material was a $304 \mathrm{~L}$ stainless steel welding wire with a diameter of $0.8 \mathrm{~mm}$. The chemical compositions of the substrate samples and deposited wire arelisted in Table 1.The total current, $I_{\text {total }}$, was $35 \mathrm{~A}$. The initial torch stand-off distance, $H$, was $6 \mathrm{~mm}$, and it was limited to range from 5.8 to $6.2 \mathrm{~mm}$. Based on $I_{\text {total }}$ and $H$, the reference $U_{\text {bypass }}$ value was set at $1.92 \mathrm{~V}$.The values of the other parameters are presented in Table 2. A schematic of the process of depositing the molten 304L stainless steel solid wire on the sloping substrate is shown in Figure 13.

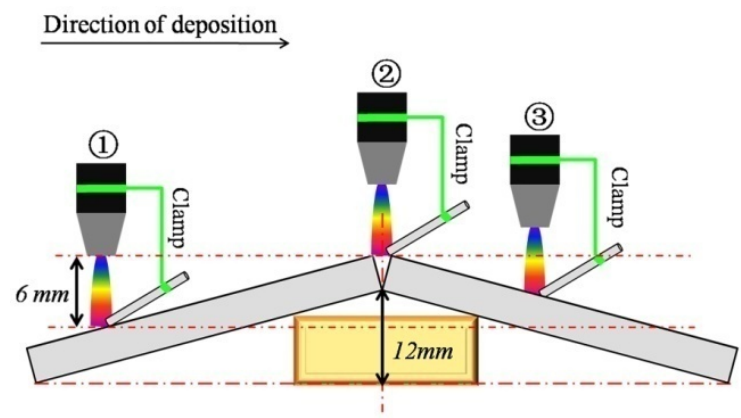

Figure13 Schematic diagram of process of depositing molten wire material on sloping substrate

Position 1 in Figure 13 corresponds to the initial state of the deposition processduring the sloping-substrate test; in this stage, $H$ was $6 \mathrm{~mm}$. In position 2, the welding torch is just above the top of the sloping substrate. In order to ensure than $H$ remains at $6 \mathrm{~mm}$ between positions 1 and 2, the welding torch is moved to a height of $6 \mathrm{~mm}$ along the ascending branch of the sloping substrate till position 2 . From the position 2 to position 3, the welding torch is moved gradually along the descending branch. In this manner, the sloping-substrate test was performed to evaluate the ability of the self-adaptive DE-MPAW control system to track the continuous changes in $H$ while depositing a metallic material on a complex-shaped substrate.

As shown in Figure 14, a smooth and defect-less weld bead was deposited successfully on the sloping substrate using the control system. The changes in the torch stand-off distance were determined based on photographs taken by the CP- 80 camera. At the $11.02^{\text {th }} \mathrm{s}$, the value of $H$ as the torch moved over the ascending branch of the sloping substrate was $5.2 \mathrm{~mm}$; at the $21.02^{\text {th }} \mathrm{s}$, the value of $H$ was $5.9 \mathrm{~mm}$, and the torch was above the top of the substrate; finally, at the $38.04^{\text {th }} \mathrm{s}$, the value of $H$ as the torch moved over the descending branch of the substrate was $6.5 \mathrm{~mm}$.

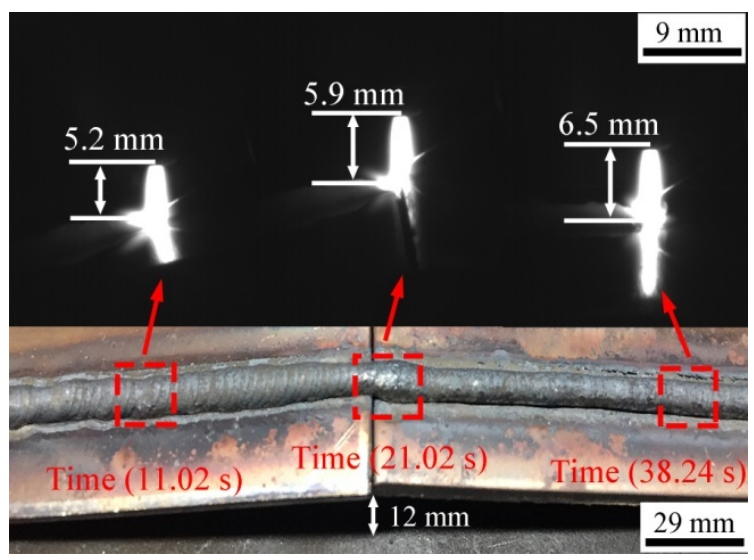

Figure14 Changes intorch stand-off distance during sloping-substrate test

Furthermore, the real-time data of the torch stand-off distance and wire feed rate during the sloping-substrate test are shown in Figure 15.

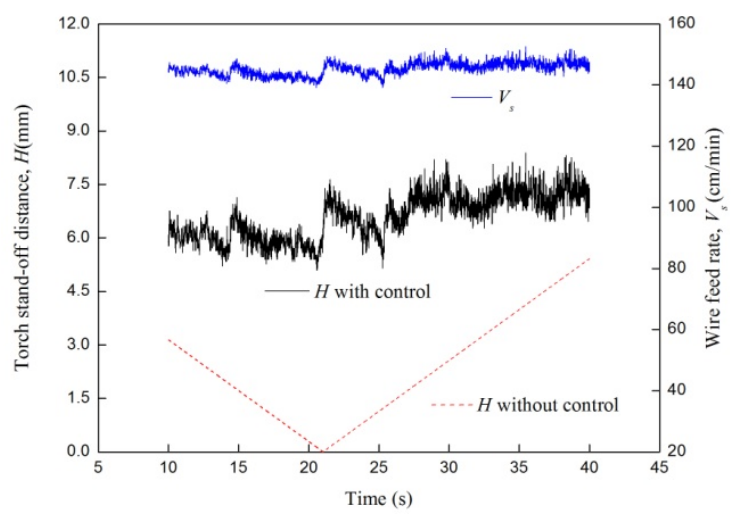

Figure15 Total voltage and wire feed rate during sloping-substrate test

The fluctuations in $H$ as the torch moved over the ascending branch were less than those in the case of the descending branch. Besides, the average value of $H$ is about $6.0 \mathrm{~mm}$ during the ascending branch while it is about $7.0 \mathrm{~mm}$ during the descending branch. The maximum average error of $H$ is about $1.0 \mathrm{~mm}$ happening in the descending branch.

However, if the welding torch were to move towards the top of the slope in the absence of a control system, the 
torch stand-off distance would decrease continuously and becomes zero at the top of the substrate. Moreover, the torch stand-off distance would gradually increase to $6.0 \mathrm{~mm}$ when moving down along the slop. This process of $H$ is shownand labeled as the " $H$ without control" in Figure 15.

In contrast, the $H$ fluctuations were significantly larger when the self-adaptive control system was used. This confirmed that the $H$ fluctuations can be effectively controlled by the self-adaptive control system during the entire sloping-deposition process. Besides, the control system still need to be improved to decreases the error of $\mathrm{H}$ during the deposition process in the descending branch.

\subsection{Tests involving deposition of single-walled component and metal part in form of Chinese language character}

To deposit ametal part in form of Chinese language character “中”, the total current used was 35A, and the torch stand-off distance ranged from 4.8 to $5.2 \mathrm{~mm}$. Further, the reference bypass voltage corresponding to the bridging-transfer model was set at $1.6 \mathrm{~V}$. The values of the other parameter are presented in Table 2. The deposition paths for the Chinese character are presented in Figure 16.

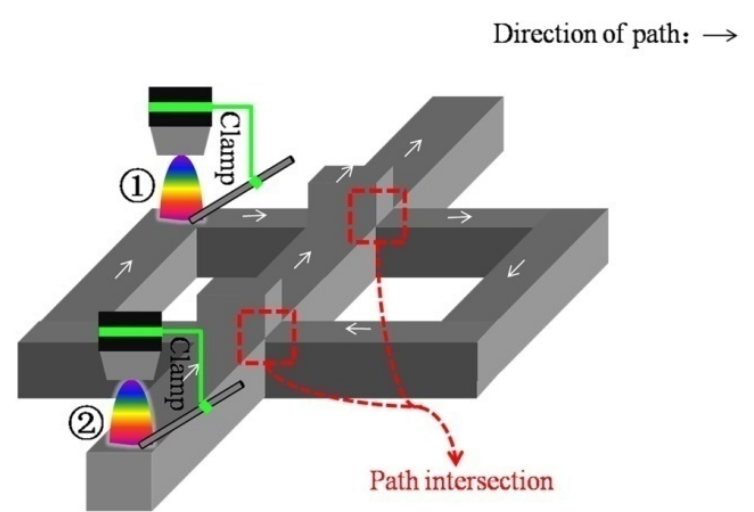

Figure16 Schematic of depositing the metal material in form of Chinese characters using self-adaptive DE-MPAW control system.

In the case of the first path, the welding torch started from position 1 . The process of deposition was performed in the clockwise direction, and the torch returned to position 2. For the second deposition path, the welding torch started from position 2 and deposited material directly across the first deposition path. Hence, this test included cross-paths, which pose a significant challenge during WAAM deposition.

As can be seen from Figure 17, the metal part in form of Chinese character "中” is successfully deposited by the self-adaptive DE-MPAW control system. The torch stand-off distance and wire feed rate corresponding to the second deposition path are given in Fig.18. Compared to the case during the movement of the welding torch towards the path intersections in the absence of a control method, the fluctuations in the torch stand-off distance when the self-adaptive control system was used were relatively smaller. In addition, the wire feeding rate was low when the torch moved across the path intersections.

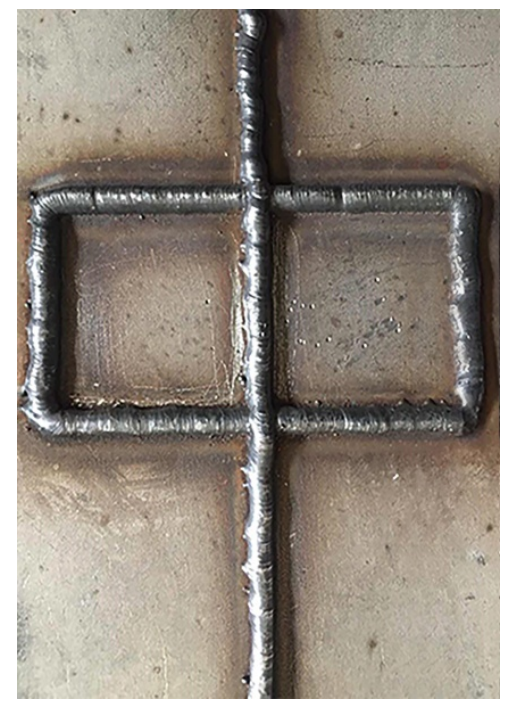

Figure17 Metal part in form of Chinese character by self-adaptive DE-MPAW control system

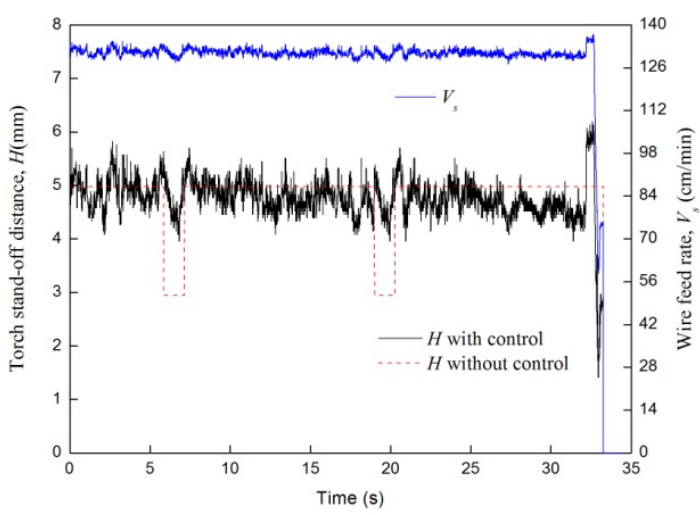

Figure18 Voltage and wire feed rate forsecond deposition path.

The single-walled component is deposited to evaluate whether the self-adaptive DE-MPAW control system can make the design of the deposition path in height orientation simpler.

The total current was $35 \mathrm{~A}$, and the torch stand-off distance was set to range from 5.8 to $6.2 \mathrm{~mm}$. The reference $U_{\text {bypass }}$ value was $1.92 \mathrm{~V}$. The values of the rest of the parameters were the same as those in Table 2. The deposition paths for the single-walled component are shown in Figure 19. The single-walled component 
required the deposition of 20 layers, and the deposition direction of each layer had to be the alternating. Moreover, after the deposition of every layer, the welding torch had to be automatically adjusted to the next layer to ensure that the torch stand-off distance did not vary significantly.

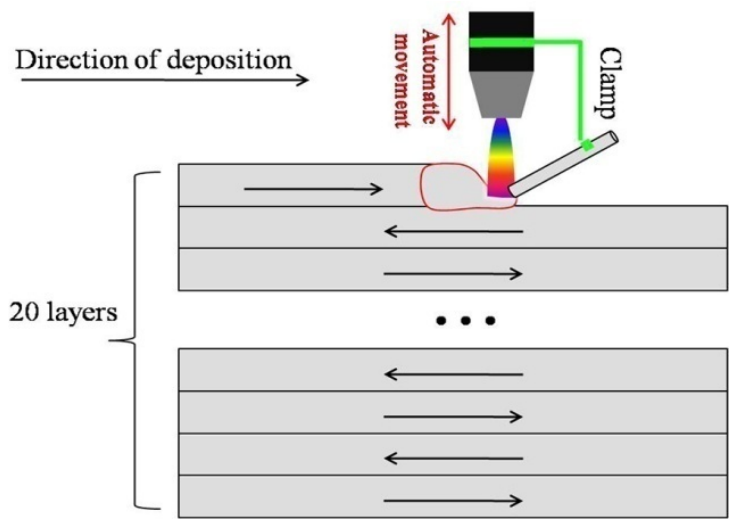

Figure19 Schematic of deposition of single-walled component using proposed self-adaptive control system

The single-walled component consisting of 20 layersas deposited by the self-adaptive control system is shown in Figure 20.

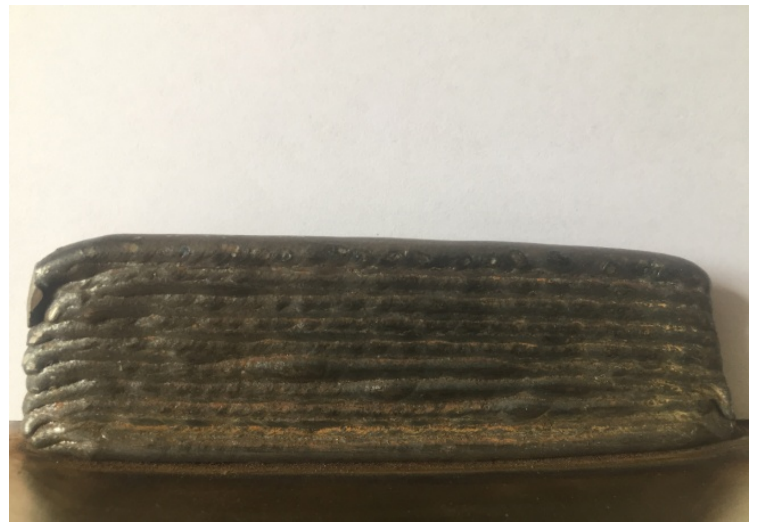

Figure20 Single-walledcomponent deposited using proposed self-adaptive control system

While the part has a rough appearance, indicating that the accuracy of the control system needs to be improved further, it can be seen that the system could successfully deposit the multiple layers to form the component without significant variations in the deposition height. The issue of the collapse of single-walled components formed by WAAM processes could be overcome with the control system. This was because the amount of heat flowing into the deposited layers and the substrate is reduced by the bypass current loop, and the welding torch can move up and down automatically to track the deposited layers. This prevents outside interferences from affecting the arc length. Moreover, the control system allowed the two-dimensional deposition process to be transformed into a one-dimensional one with having to determine the final height of the deposited layers in advance.

The dynamic changes in the deposition parameters during the deposition of $1^{\text {th }} \sim 10^{\text {th }}$ of the single-walled component are presented in Figure 21.

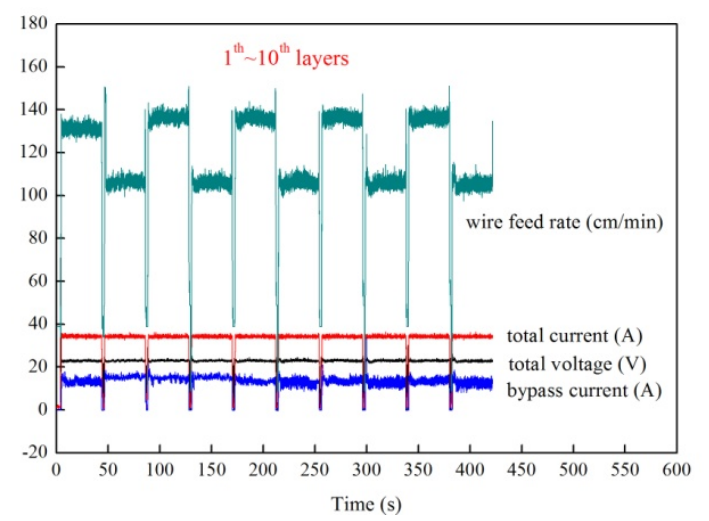

Figure 21 Parameters data collected in the deposition process of the $1^{\text {th }} \sim 10^{\text {th }}$ layers

After the deposition of each layer, the main arc will turn off automatically for 2 seconds to make sure solidification of the molten pool before the next deposition. And the wire feed rate in the odd layers was set about $20 \mathrm{~cm} / \mathrm{min}$ higher than the even layers. Because the wire is filled into the front-end of molten pool in the deposition process of the odd layers, and filled into the back-end of molten pool in the deposition process of the even layers. The total voltage, and bypass current remained relatively constant during the deposition process of the first ten layers. The bypass current is about 0.5 times of total current, which means the heat flowed through the deposited layers and substrate is effectively reduced and improved.

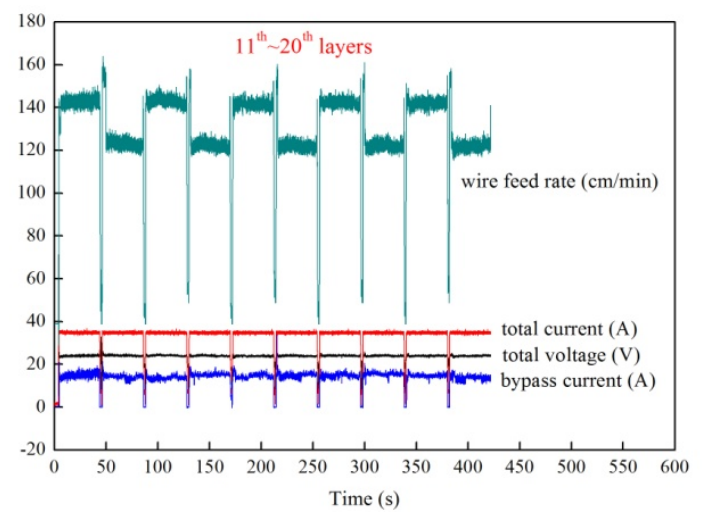

Figure22 Parameters data collected inthe deposition process of the $11^{\text {th }} \sim 20^{\text {th }}$ layers

As presented in Figure 22, the total voltage and bypass current also remain relatively constant in the deposition 
process of the last ten layers. But the wire feed ratesare larger than the values in the deposition process of the first ten layers. One reason for this phenomenon is that, because of the heat accumulation, with an increase of the deposited layers, the width of molten pool become larger when the height of molten pool become lower, especially in the deposition process of the last ten layers. Therefore, by using the self-adaptive control system, the wire feed rate increased automatically in the last ten layers effectively made up for the liquid metal flowing away from the molten pool. The collapsed phenomenon of the deposited layers can also be improved by this self-adaptive control system.

\section{Conclusions}

In this study, we developed an innovative control system for AM via DE-MPAW and evaluated it using a series of deposition tests.The main conclusions of the study are presented as follows:

(1) For the DE-MPAW deposition process, the bridging-transfer model is the most suitable for ensuring a higher wire feeding rate to improve the deposition efficiency. Further, both the bypass current and the voltage can be used as indexes to evaluate metal transfer into the weld pool.

(2) Using the proposed self-adaptive DE-MPAW control system, we successfully deposited a metallic material on different-shaped substrates. Thus, it was confirmed that the system protects the deposition process of WAAM from the interferences of torch stand-off distance and this system can be potentially applied to repair of complex surface metal parts.

(3) The deposition path design of WAAM is simplified and optimized by automatically moving the welding torch up or down in the height direction of the deposited parts.

(4) The collapsing of the weld pool result from overheating during the WAAM process is improved. Because the heat input of the deposited layers and substrate is reduced by the bypass current and the control system can self-adaptively adjust the wire feed rate and torch stand-off distance real-time in the process of WAAM.

\section{Declaration}

\section{Ethics approval and consent to participate}

The manuscript is ethically approved and all authors agree toparticipate.

\section{Publication}

The authors all agree to publish.

Availability of data and materials

All authors promise that materials and data are authentic.

\section{Authors' Contributions}

LI Nan wrote the manuscript; FAN Ding assisted in English translation; HUANGJiankang, YU Shurong, YUANWen and HANMiaomiao assistedin numerical analysis and experimental verification. All authors read and approved the fnal manuscript.

\section{Competing Interests}

The authors declare no competing financial interests.

\section{Biographical notes}

LI Nan, is a currently master degree candidate in Lanzhou University of Technology, China. His research interests include additive manufacturing.

E-mail: linan128@126.com

FAN Ding, is currently a professor in Lanzhou University of Technology, China. His research interests include numerical simulation of welding and arc additive manufacturing.

E-mail: fand@lut.cn;

HUANG Jiankang, is currently an associate professor in Lanzhou University of Technology, China. His research interests include numerical simulation of welding and arc additive manufacturing.

E-mail: sr2810@163.com

YU Shurong, is currently a professor in Lanzhou University of Technology, China. Her research interests include arc additive manufacturing.

E-mail: yushur1991@163.com.

YUAN wen, is a currently master degree candidatein Lanzhou Universityof Technology, China. His research interests include additive manufacturing.

E-mail:18735476801@163.com

HAN MiaoMiao, is a currently master degree candidatein Lanzhou Universityof Technology, China. Her research interests include numerical simulation of welding and 
additive manufacturing.

E-mail: hmm106107@163.com

\section{Acknowledgements}

We are grateful for the technical and financial support provided by Lanzhou University of Technology,National Natural Science Foundation of China.

\section{Funding}

This work was funded by National Natural Science Foundation of China (No.51665034).

\section{References}

[1] K V Wong, A Hernandez. A review of additive manufacturing. Isrn Mechanical Engineering, 2012, 2012(2): 30-38.

[2] D Ding, Z Pan, D Cuiuri, et al. Wire-feed additive manufacturing of metal components: technologies, developments and future interests. International Journal of Advanced Manufacturing Technology, 2015, 81: 465-481.

[3] S W Williams, F Martina, A C Addison, et al. Wire + arc additive manufacturing. Materials Science \& Technology, 2016, 32(7): 641-647.

[4] IvánTabernero, A Paskual, P Álvarez, et al. Study on arc welding processes for high deposition rate additive manufacturing. Procedia Cirp, 2018, 68: 358-362.

[5] D Ding, Z Pan, D S Van, et al. Fabricating superior NiAl bronze components through wire arc additive manufacturing. Materials, 2016, 9(8): 652-664.

[6] J D Spencer, P M Dickens, C M Wykes. Rapid prototyping of metal parts by three-dimensional welding. Proceedings of the Institution of Mechanical Engineers Part B Journal of Engineering Manufacture, 1998, 212(3): 175-182.

[7] D Yang, G Wang, G Zhang. Thermal analysis for single-pass multi-layer GMAW based additive manufacturing using infrared thermography. Journal of Materials Processing Technology, 2017, 244: 215-224.

[8] X Chen, J Li, Z Huang, et al. Microstructure and mechanical properties of the austenitic stainless steel $316 \mathrm{~L}$ fabricated by gas metal arc additive manufacturing. Materials Science \& Engineering A, 2017, 703: $567-577$.

[9] F Martina, J Mehnen, S W Williams, et al. Investigation of the benefits of plasma deposition for the additive layer manufacture of Ti-6Al-4V. Journal of Materials Processing Technology, 2012, 212(6): 1377-1386.

[10] S Jhavar, N K Jain, C P Paul. Development of micro-plasma transferred arc ( $\mu$-PTA) wire deposition process for additive layer manufacturing applications. Journal of Materials Processing Tech, 2014, 214(5): 1102-1110.

[11] E M Qureshi, A M Malik, N U Dar. Thermo-mechanical analysis of residual stresses in arc welded thin-walled cylinders. Proceedings of the 16th International Conference on Nuclear Engineering, Florida, USA, May 11-15, 2008: 139-147

[12] J Ding, P Colegrove, J Mehnen, et al. Thermo-mechanical analysis of wire and arc additive layer manufacturing process on large multi-layer parts. Computational Materials Science, 2011, 50(12): 3315-3322.

[13] D Ding, Z Pan, D Cuiuri, et al. A tool-path generation strategy for wire and arc additive manufacturing. International Journal of Advanced Manufacturing Technology, 2014, 73(4): 173-183.

[14] R Liu, Z Wang, Y zhang, et al. A smooth toolpath generation method for laser metal deposition. Proceedings of the 27th Annual International Solid Freeform Fabrication Symposium, Texas, USA, August 7-9, 2016: 1038-1046.

[15] O H Petersen, D Burdakov, A V Tepikin. Process control and development in wire and arc additive manufacturing. Cranfield University, 2012, 30(3): 218-226.

[16] B Wu, D Ding, Z Pan, et al. Effects of heat accumulation on the arc characteristics and metal transfer behavior in Wire Arc Additive Manufacturing of Ti6Al4V. Journal of Materials Processing Technology, 2017, 250: 304-312.

[17] X Bai, P Colegrove, J Ding, et al. Numerical analysis of heat transfer and fluid flow in multilayer deposition of PAW-based wire and arc additive manufacturing. International Journal of Heat \& Mass Transfer, 2018, 124: 504-516.

[18] N Kumar, P K Jain, P Tandon, et al. Toolpath generation for additive manufacturing using $\mathrm{CNC}$ milling machine. 3D Printing and Additive Manufacturing Technologies, 2018: 73-82. doi: 10.1007/978-981-13-0305-0_7

[19] D Ding, Z Pan, D Cuiuri, et al. A practical path planning methodology for wire and arc additive manufacturing of thin-walled structures. Robotics \& Computer Integrated Manufacturing, 2015, 34 8-19.

[20] G Venturini, F Montevecchi, F Bandini, et al. Feature based three axes computer aided manufacturing software for wire arc additive manufacturing dedicated to thin walled components. Additive Manufacturing, 2018, 22: 643-657.

[21] J Xiong, G Zhang. Adaptive control of deposited height in GMAW-based layer additive manufacturing. Journal of Materials Processing Technology, 2014, 214(4): 962-968.

[22] H Dong, M Cong, Y Zhang, et al. Modeling and real-time prediction for complex welding process based on weld pool. International Journal of Advanced Manufacturing Technology, 2018, 96(5): 2495-2508

[23] $\mathrm{F} \mathrm{Li}$, S Chen, $\mathrm{Z} \mathrm{Wu}$, et al. Adaptive process control of wire and arc additive manufacturing for fabricating complex-shaped components. International Journal of Advanced Manufacturing Technology, 2018, 96(2): 1-9.

[24] Z Pan, D Ding, B Wu, et al. Arc welding processes for additive manufacturing: A review. Transactions on Intelligent Welding Manufacturing, 2017, 5(1): 3-24

[25] W Gao, Y Zhang, D Ramanujan, et al. The status, challenges, and future of additive manufacturing in engineering. Computer-Aided Design, 2015, 69: 65-89.

[26] B Lu, W Zhao, Y Tang, et al. Investigation of the overlapping parameters of MPAW-based rapid prototyping. Rapid Prototyping Journal, 2006, 12(3): 165-172.

[27] Y Lu, S J Chen, Y Shi, et al. Double-electrode arc welding process: Principle, variants, control and developments. Journal of Manufacturing Processes, 2014, 16(1):93-108

[28] K Li, Y M Zhang. Modeling and control of consumable double-electrode gas metal arc welding proceeding. Proceedings of the 17th International Federation of Automatic Control World Congress, Seoul, Korea, July 6-7, 2008: 994-999.T BSheridan. Automation, and human supervisory control-telerobotics.CambridgeMA: The MIT Press, 1992. 
Figures

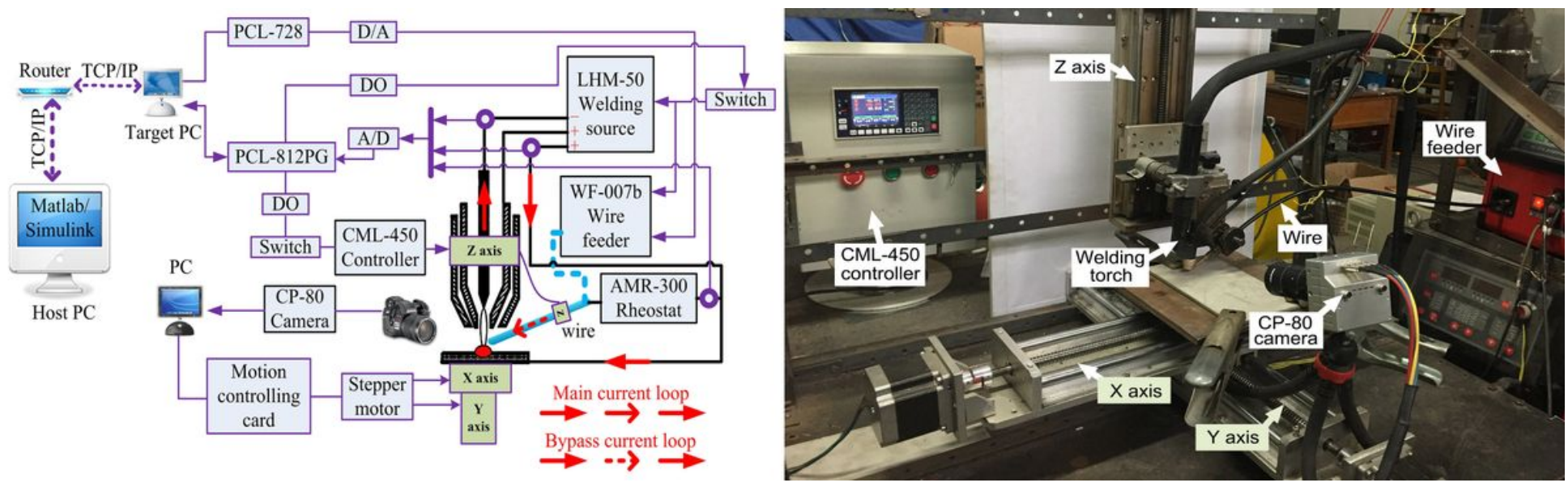

Figure 1

Experimental setup of DE-MPAW control system

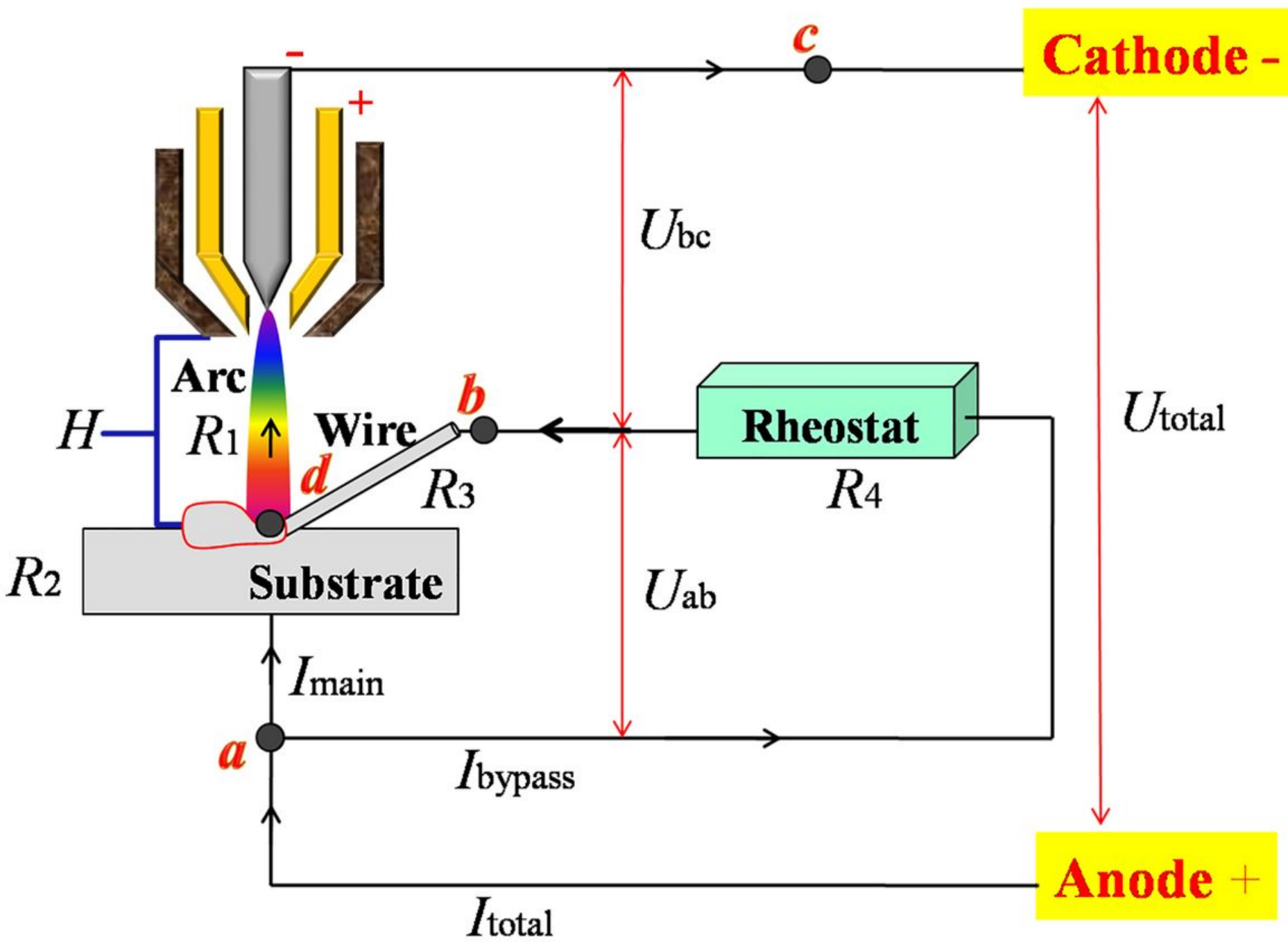

Figure 2 
Relationship between voltage and current during DE-MPAW process

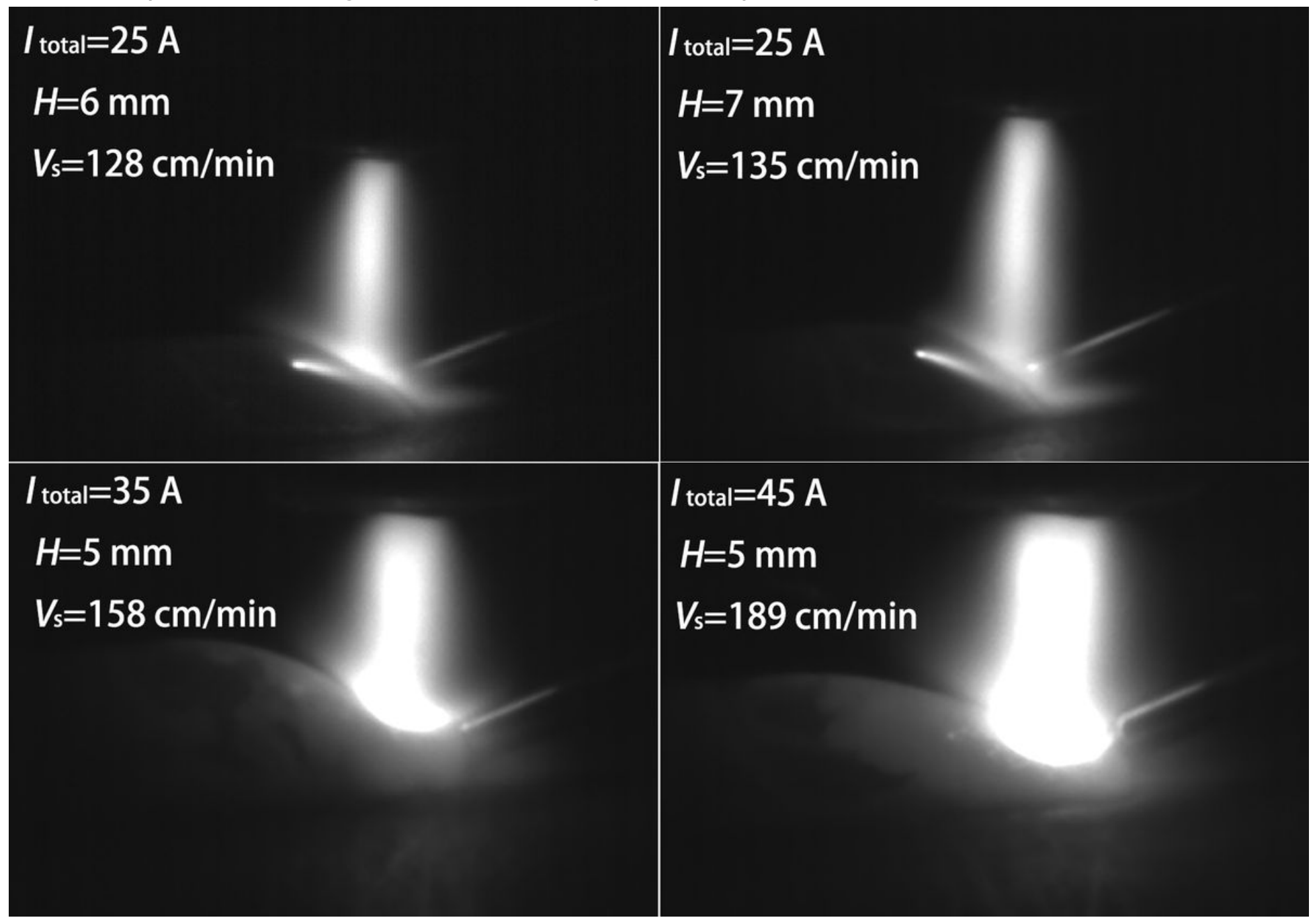

\section{Figure 3}

Metal-transfer modes corresponding to maximum wire feed rat 


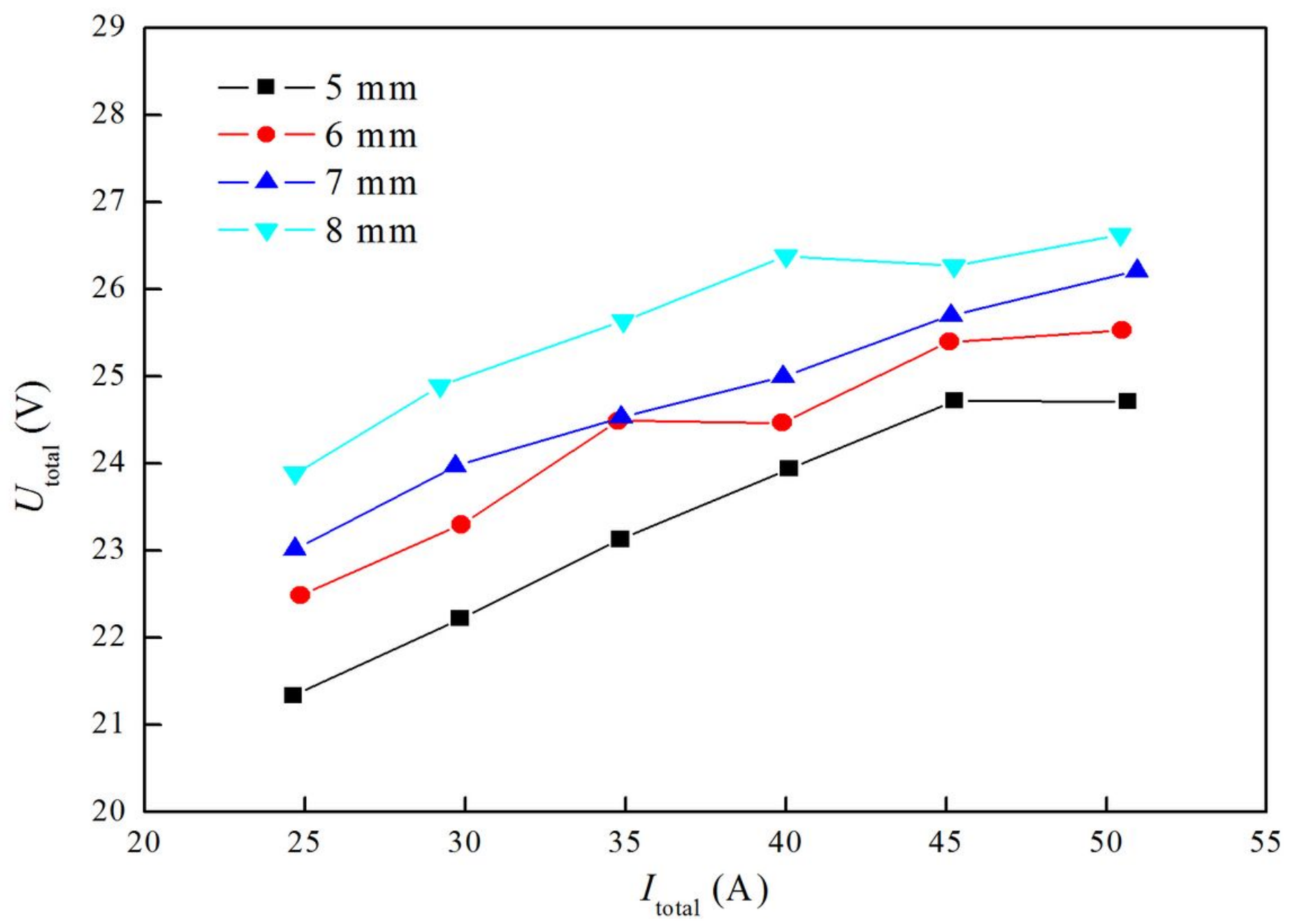

Figure 4

Relationships between total voltage and current for different torch stand-off distances. 


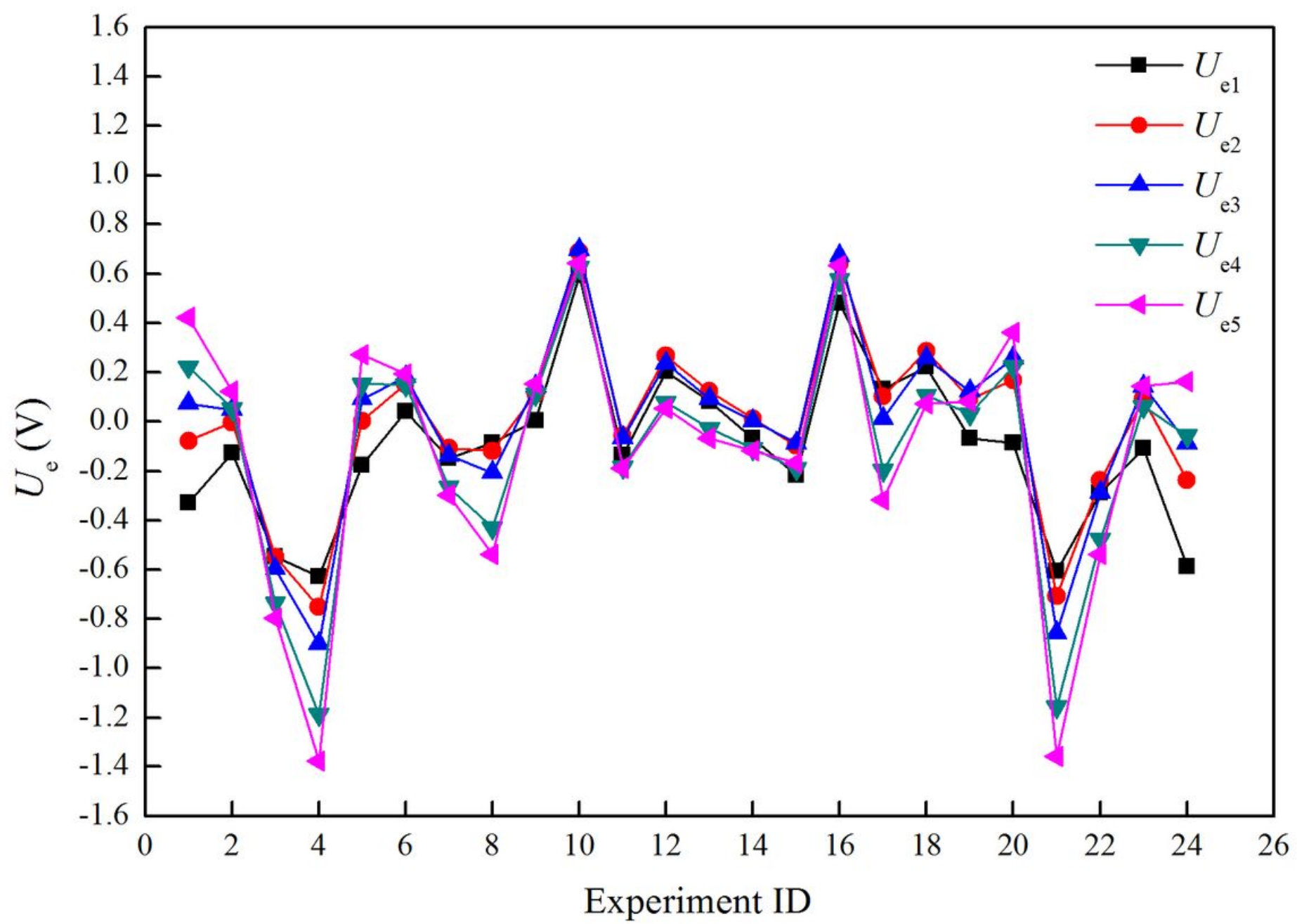

Figure 5

Error between experimentally determined and calculated total voltage values corresponding to different coefficient matrices. 


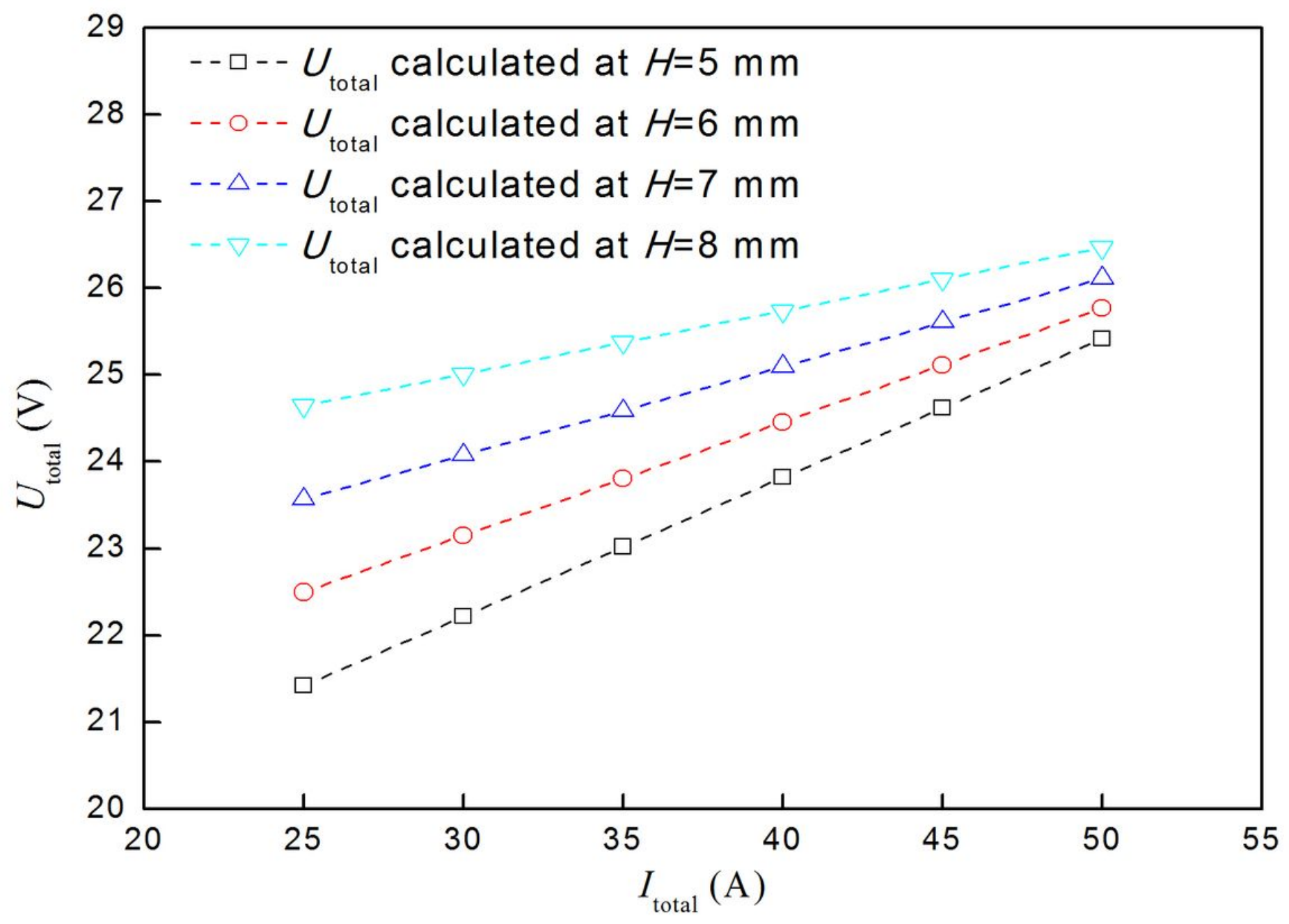

Figure 6

Relationships between calculated total voltage and total current for different torch stand-off distances 


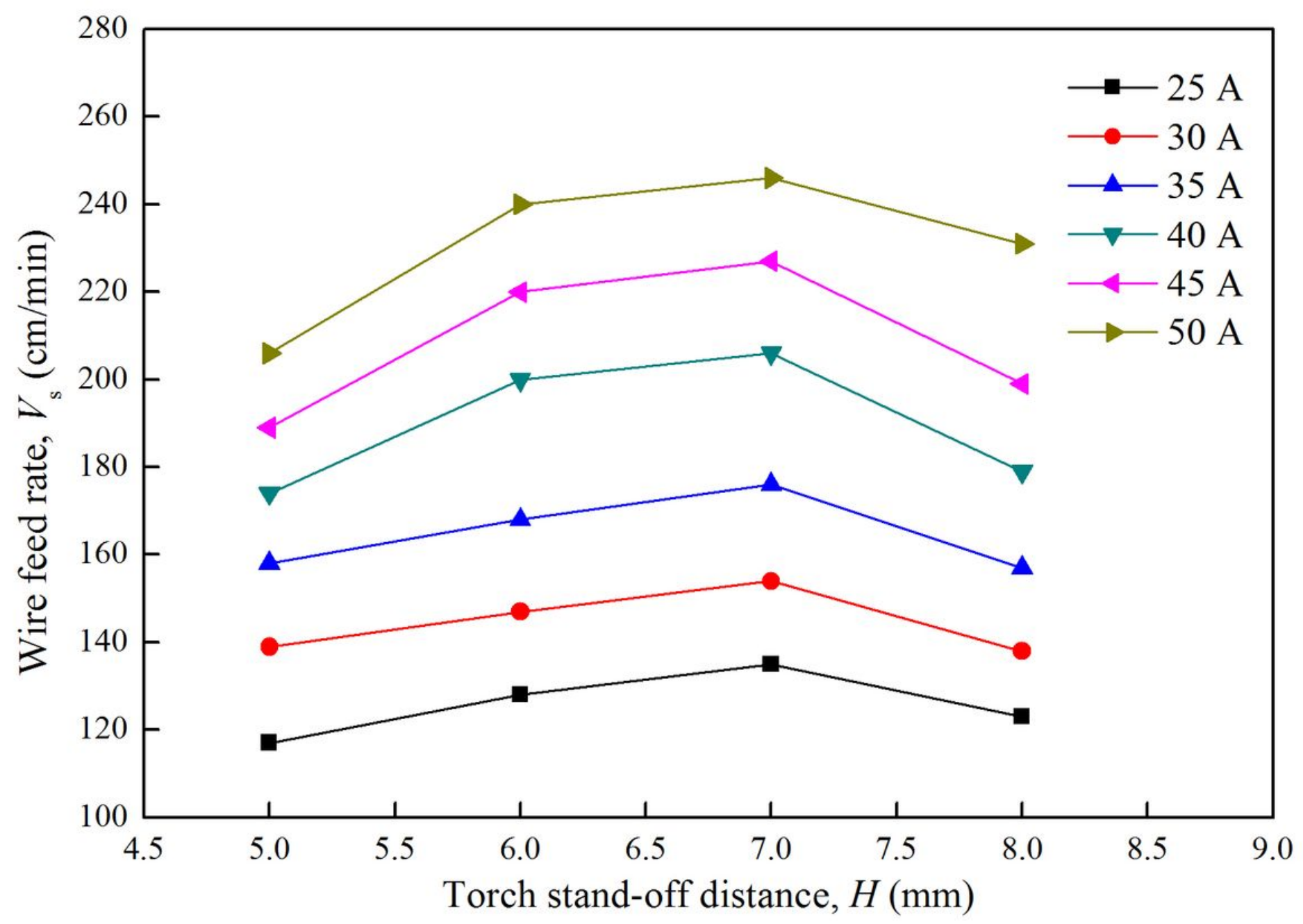

Figure 7

Relationships between wire feed rate and torch stand-off distance for different total currents 


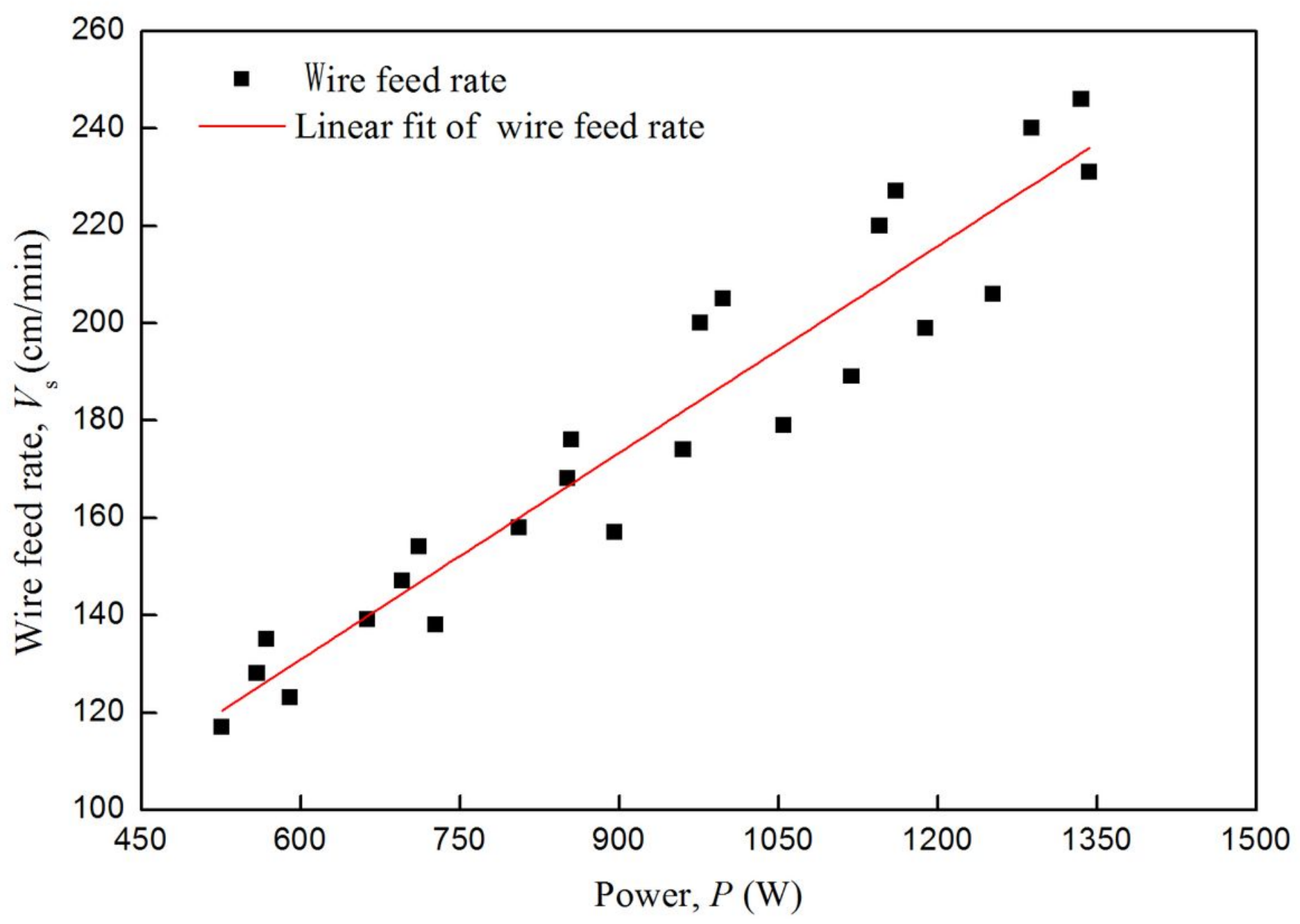

Figure 8

Relationship between wire feed rate and weld source power. 


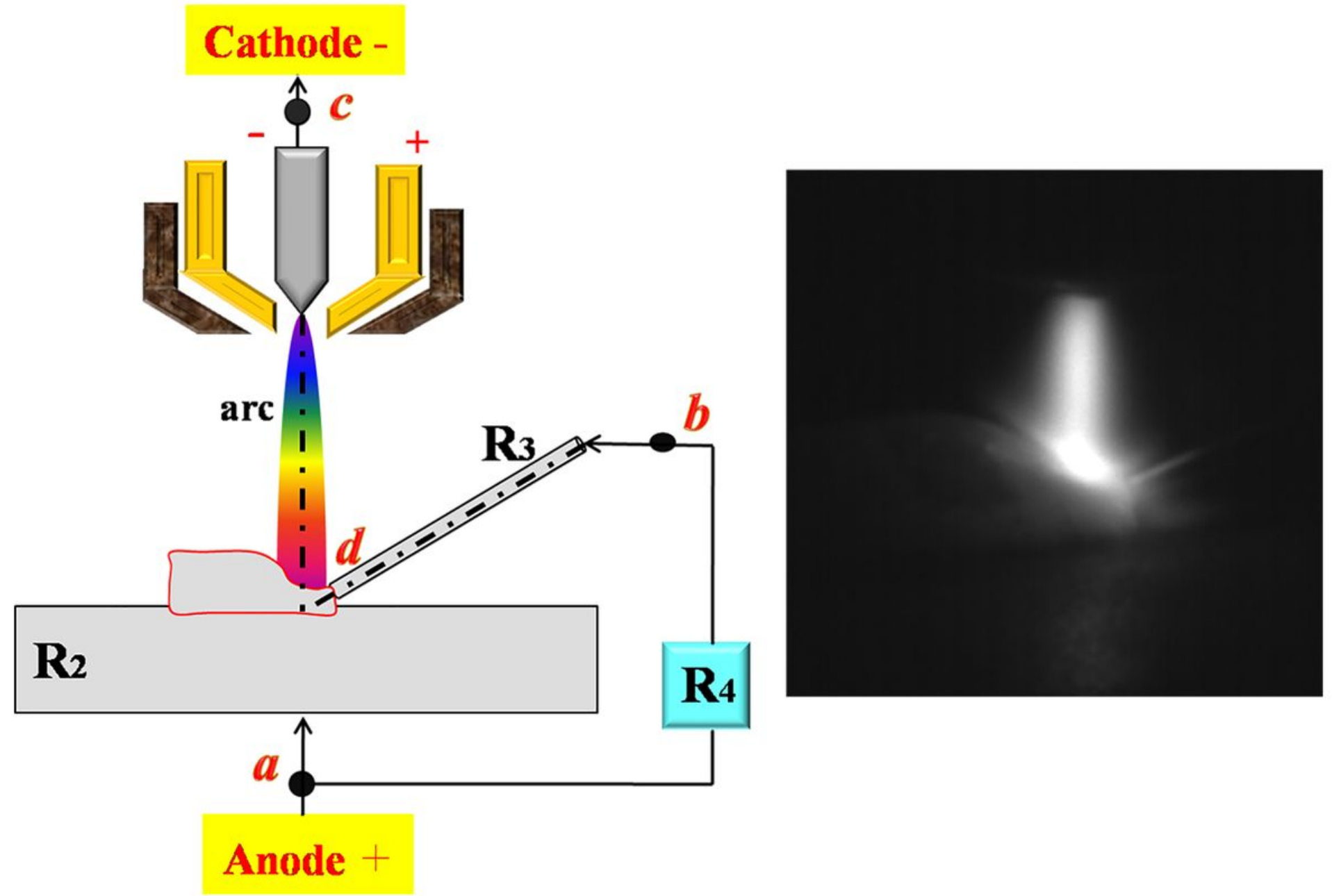

Figure 9

Circuit for DE-MPAW system in case of bridging-transfer model. 


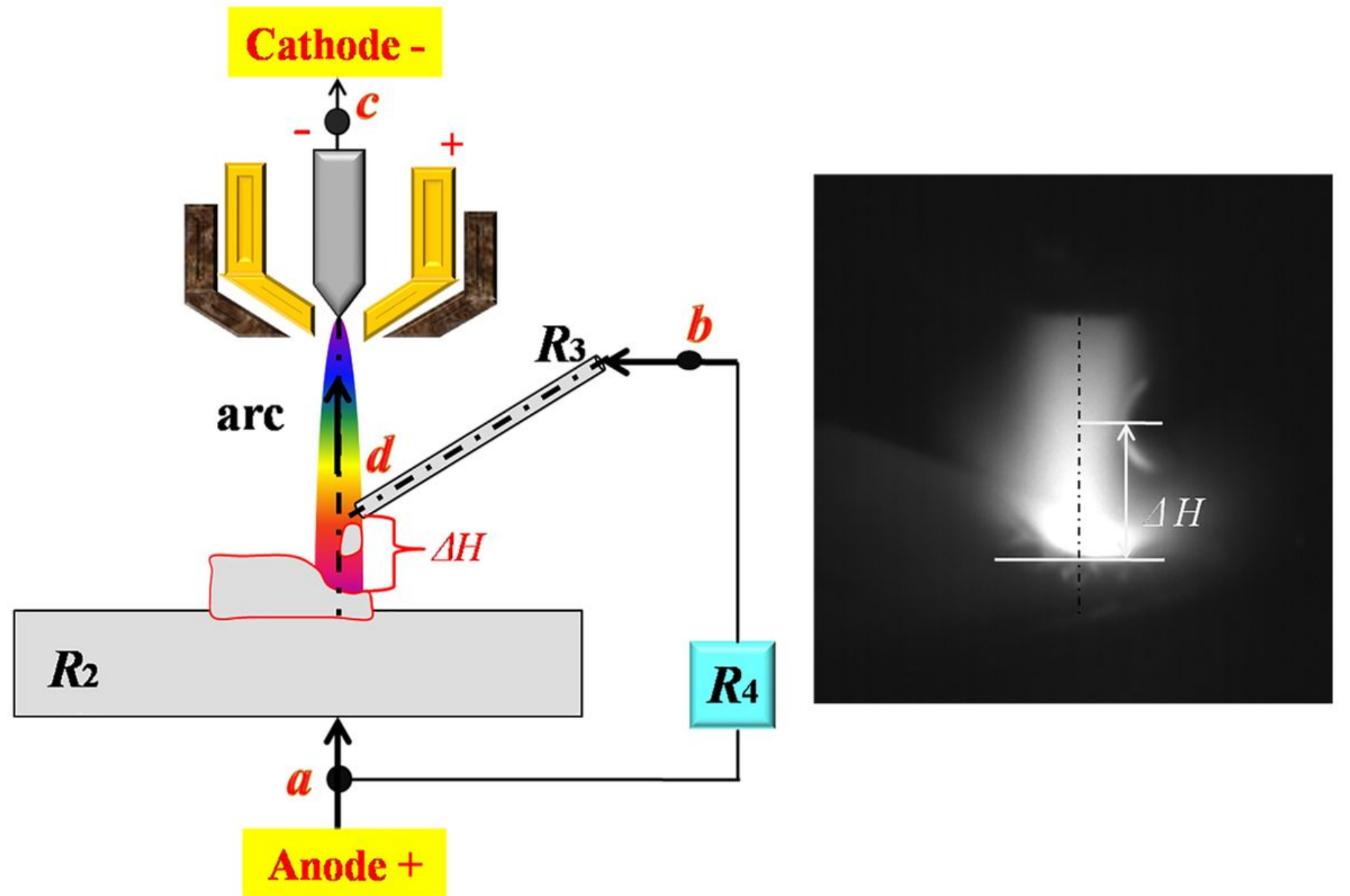

Figure 10

Circuit of DE-MPAW system corresponding to droplet-transfer model 


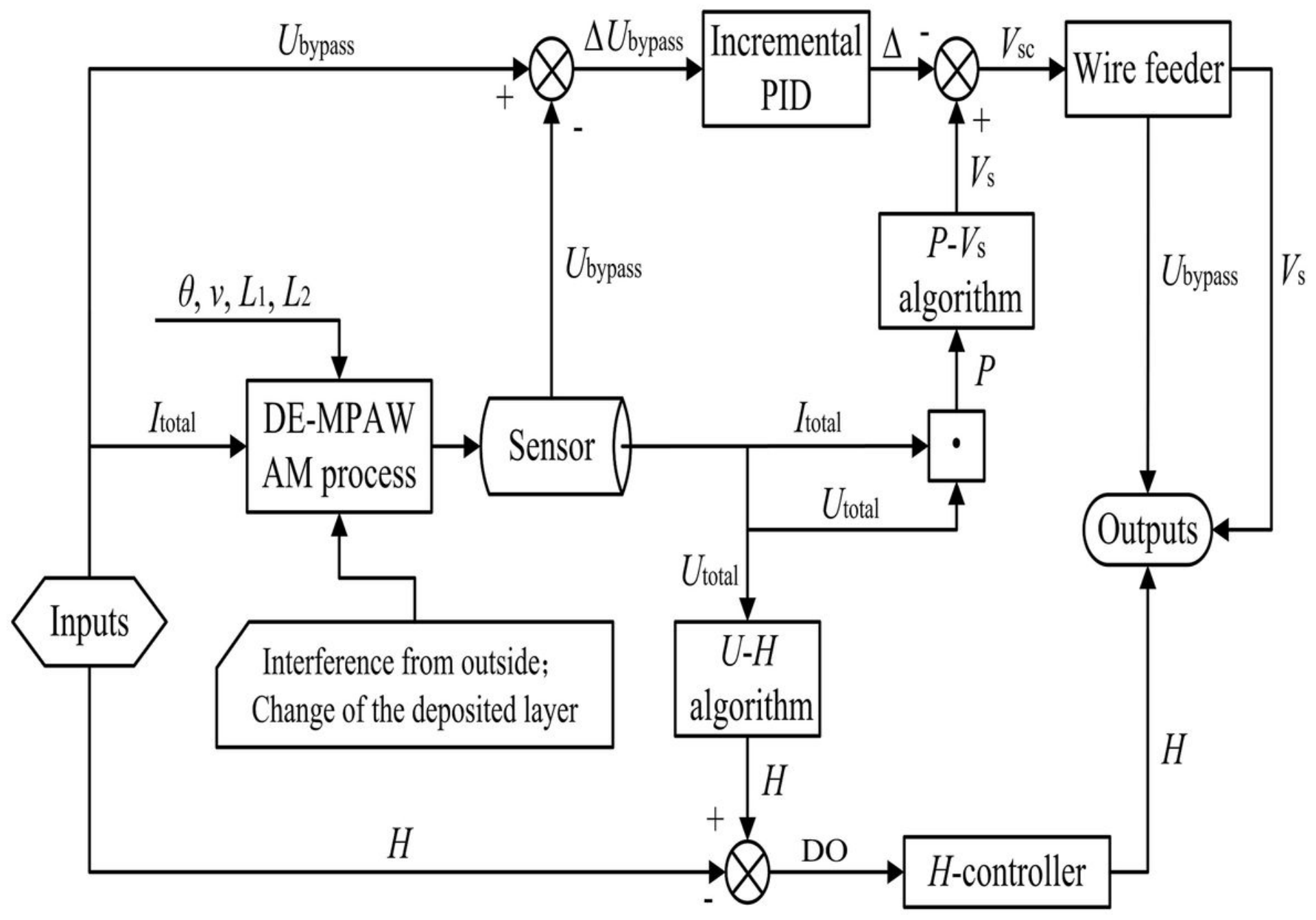

Figure 11

Structure of proposed DE-MPAW control system 


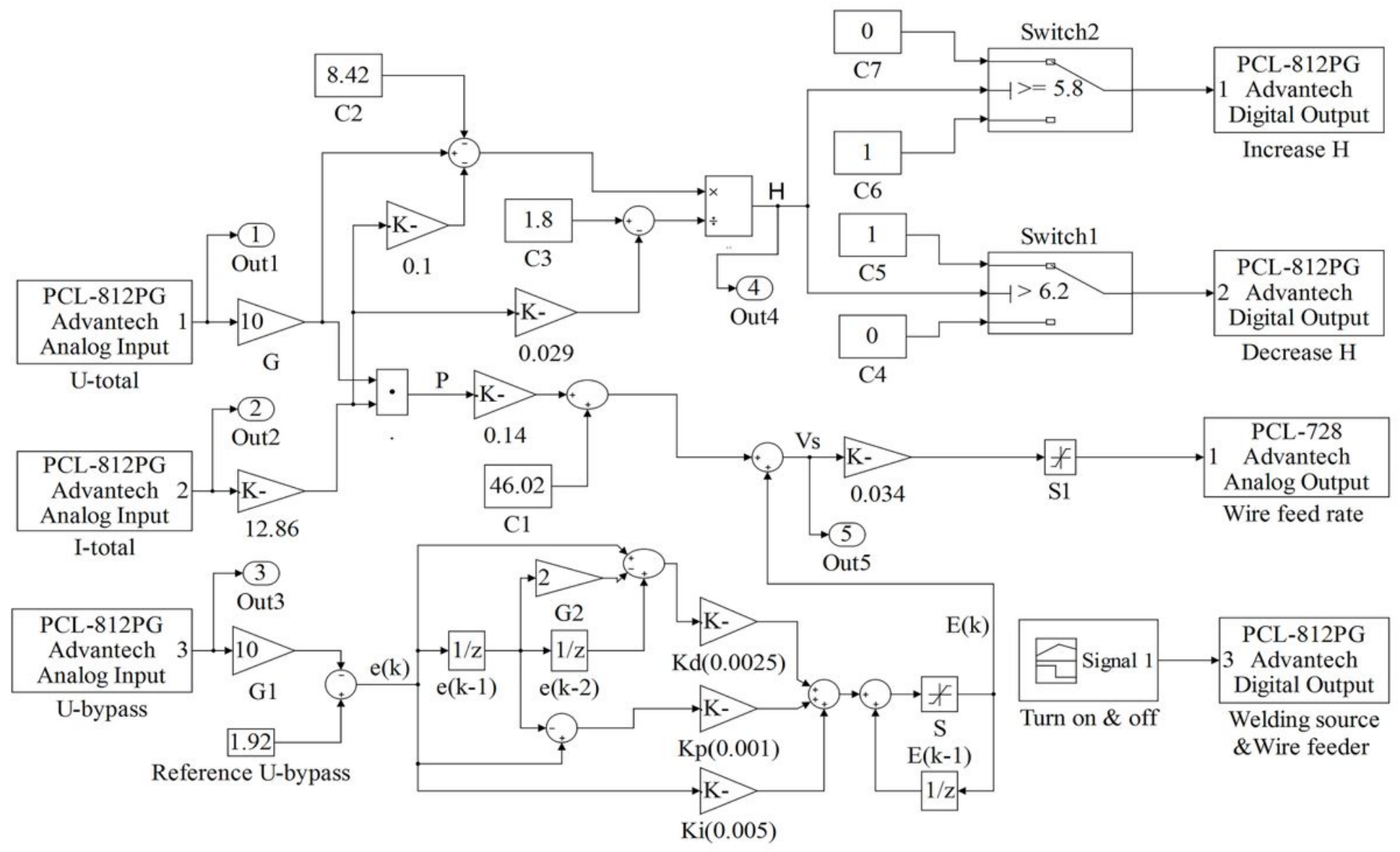

Figure 12

Diagram of self-adaptive DE-MPAW control system 


\section{$\stackrel{\text { Direction of deposition }}{\longrightarrow}$}

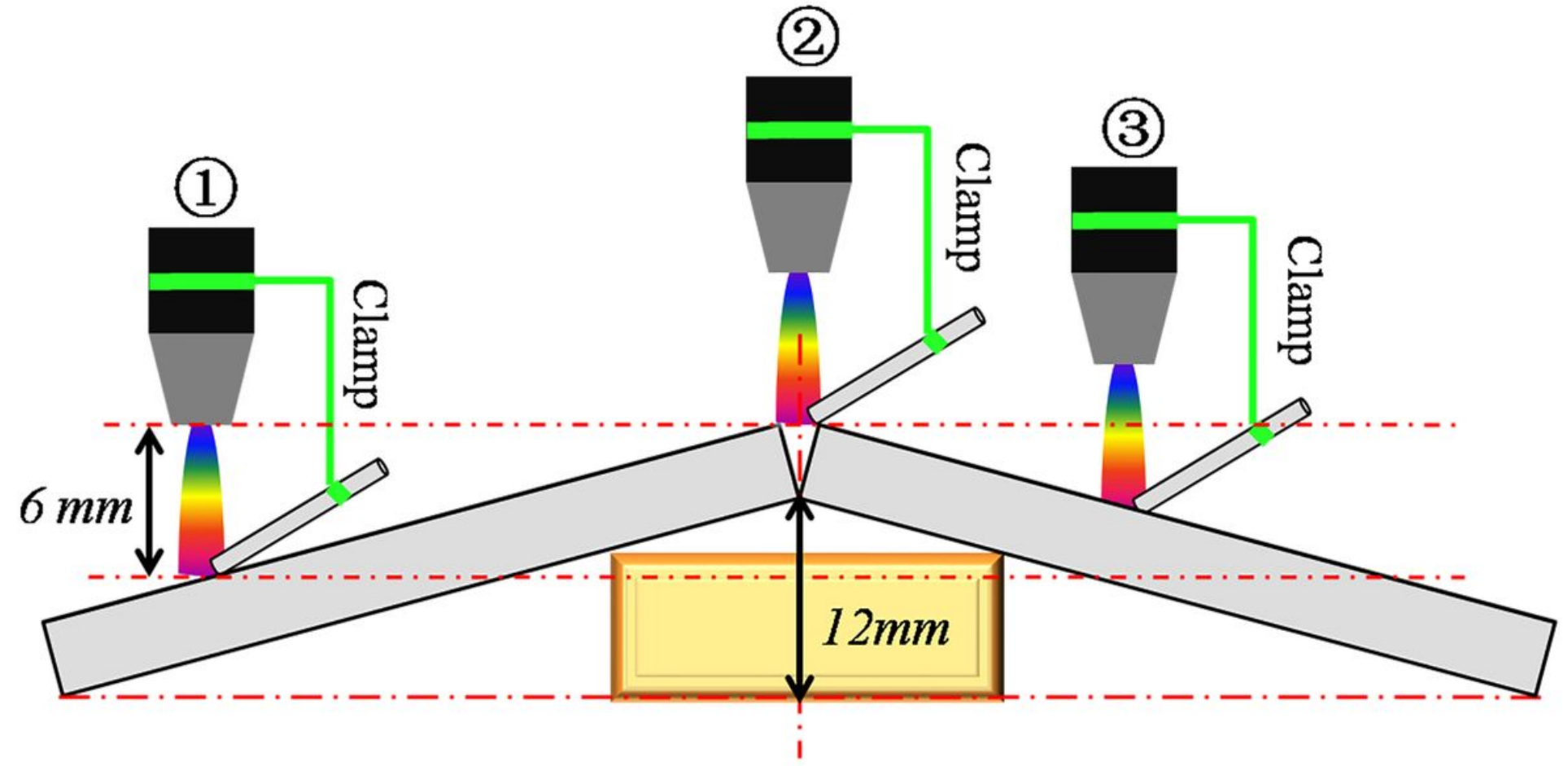

Figure 13

Schematic diagram of process of depositing molten wire material on sloping substrate 


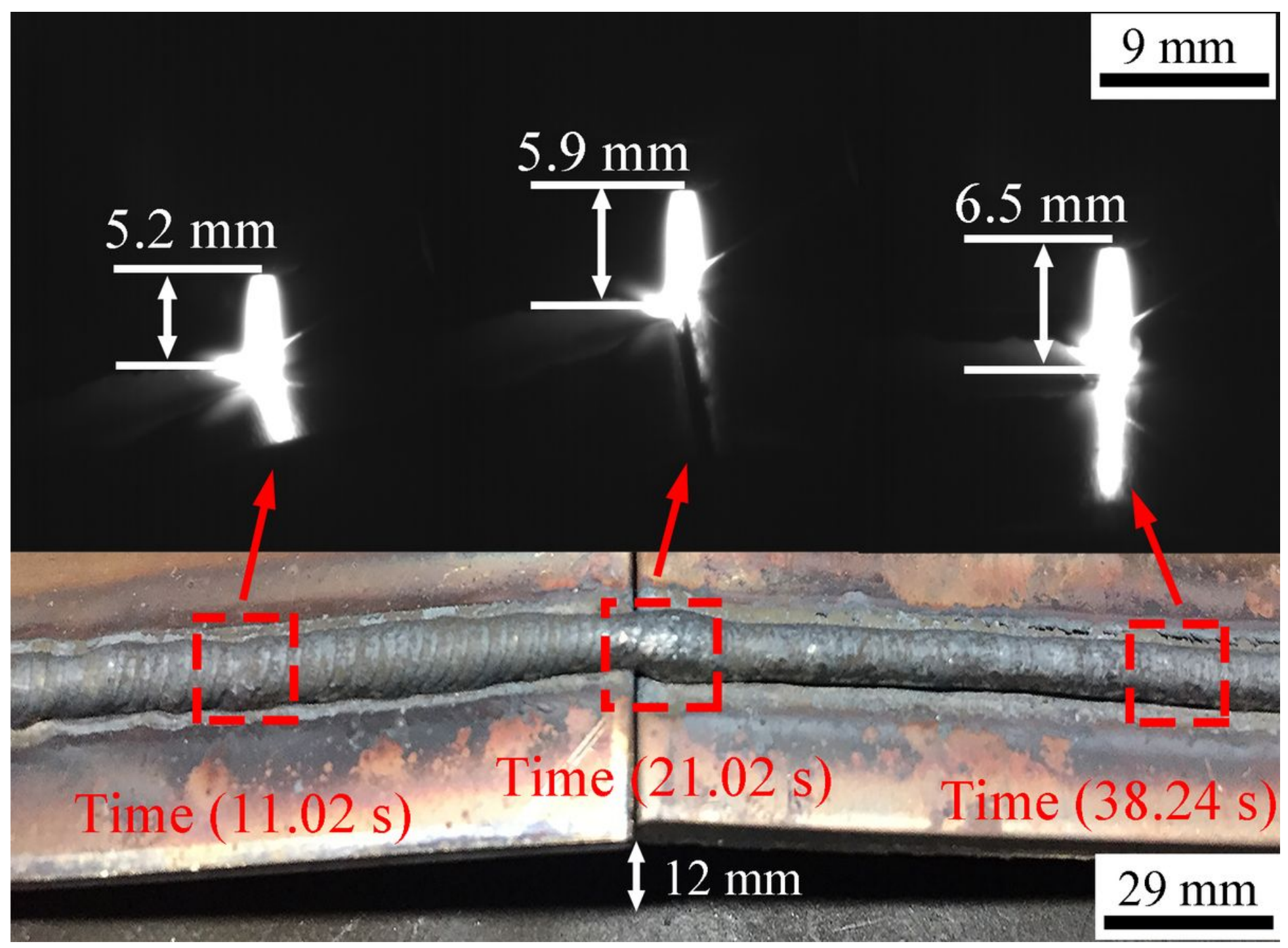

Figure 14

Changes in torch stand-off distance during sloping-substrate test 


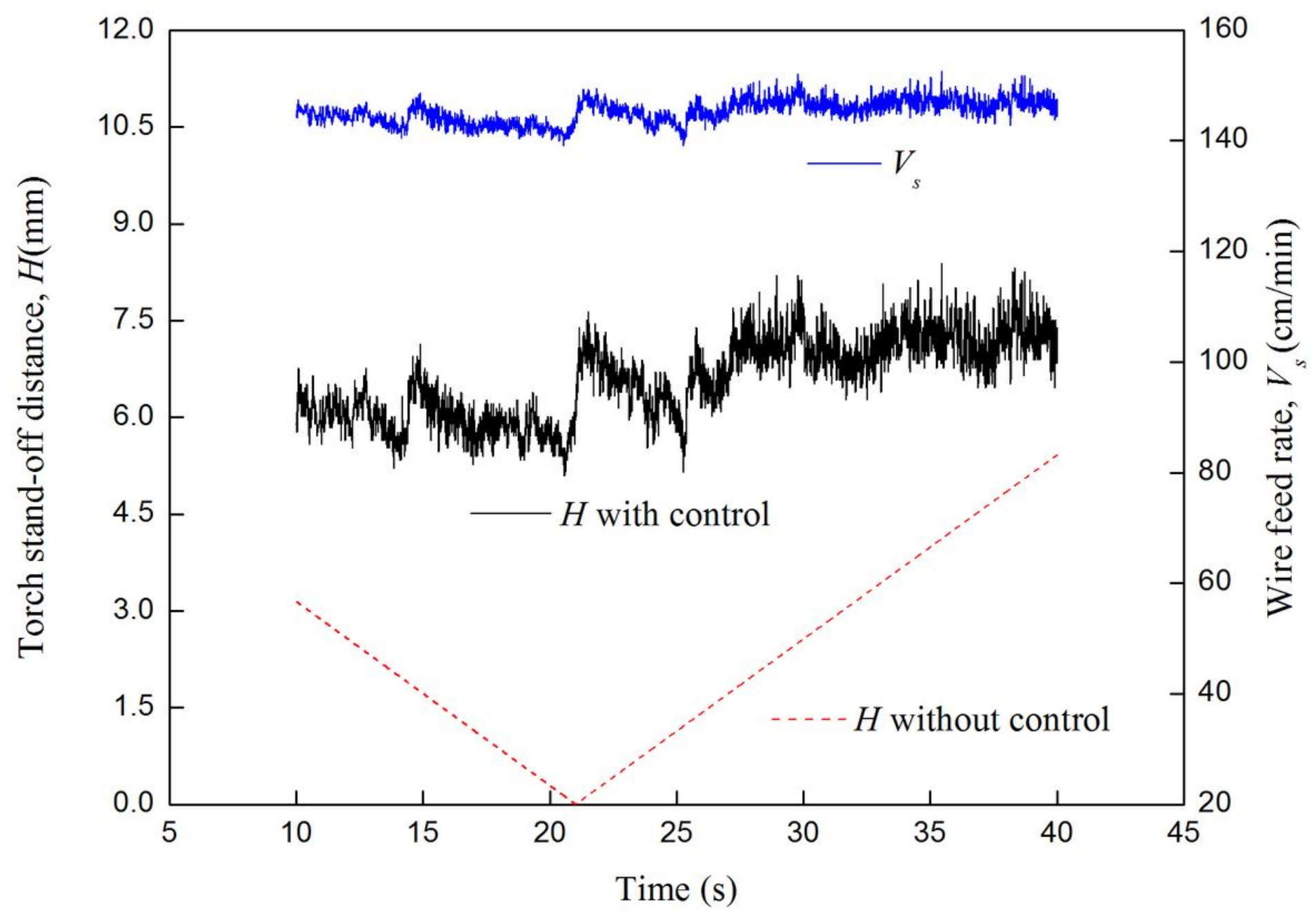

Figure 15

Total voltage and wire feed rate during sloping-substrate test 


\section{Direction of path: $\rightarrow$}

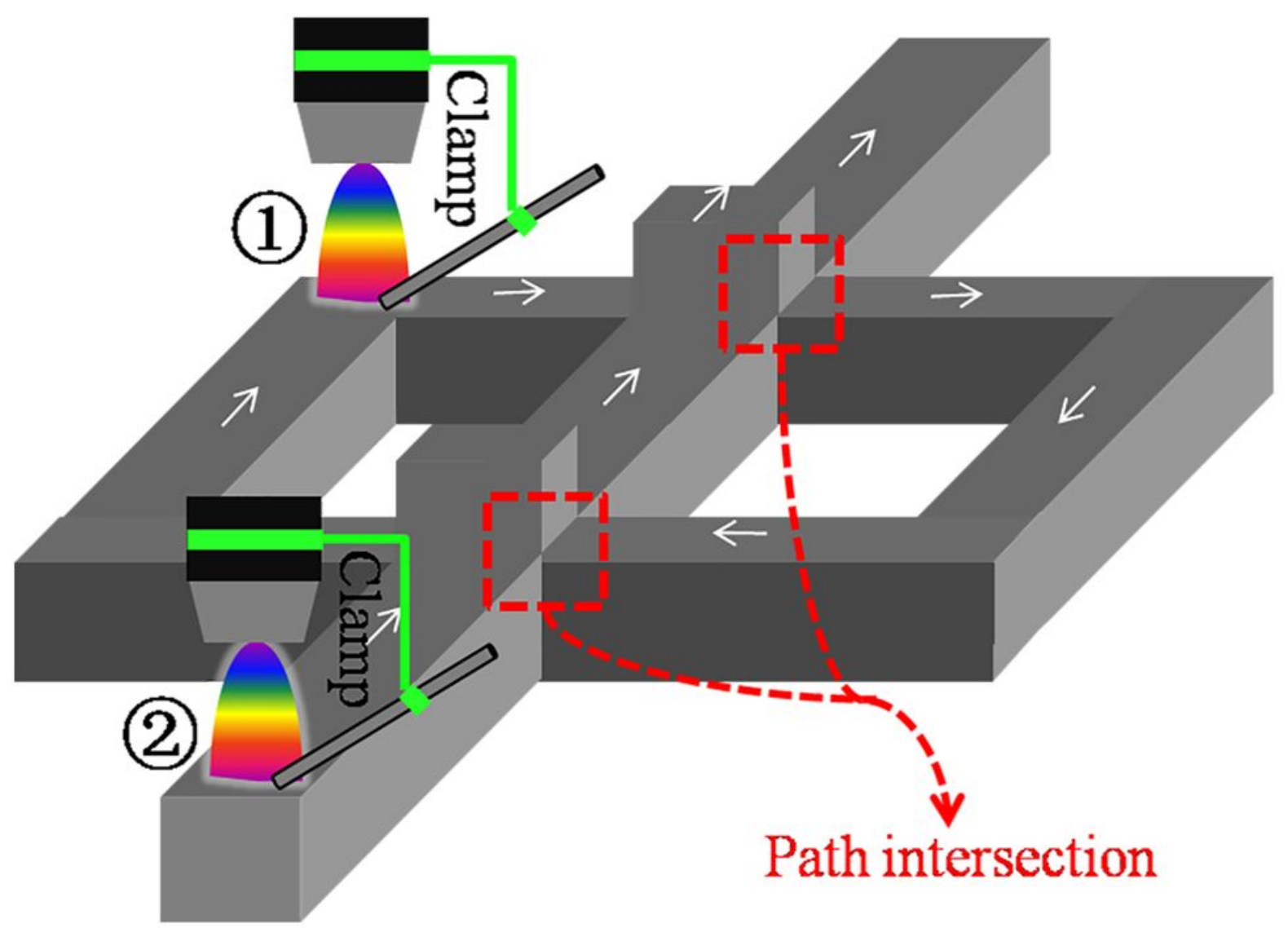

Figure 16

Schematic of depositing the metal material in form of Chinese characters using self-adaptive DE-MPAW control system. 


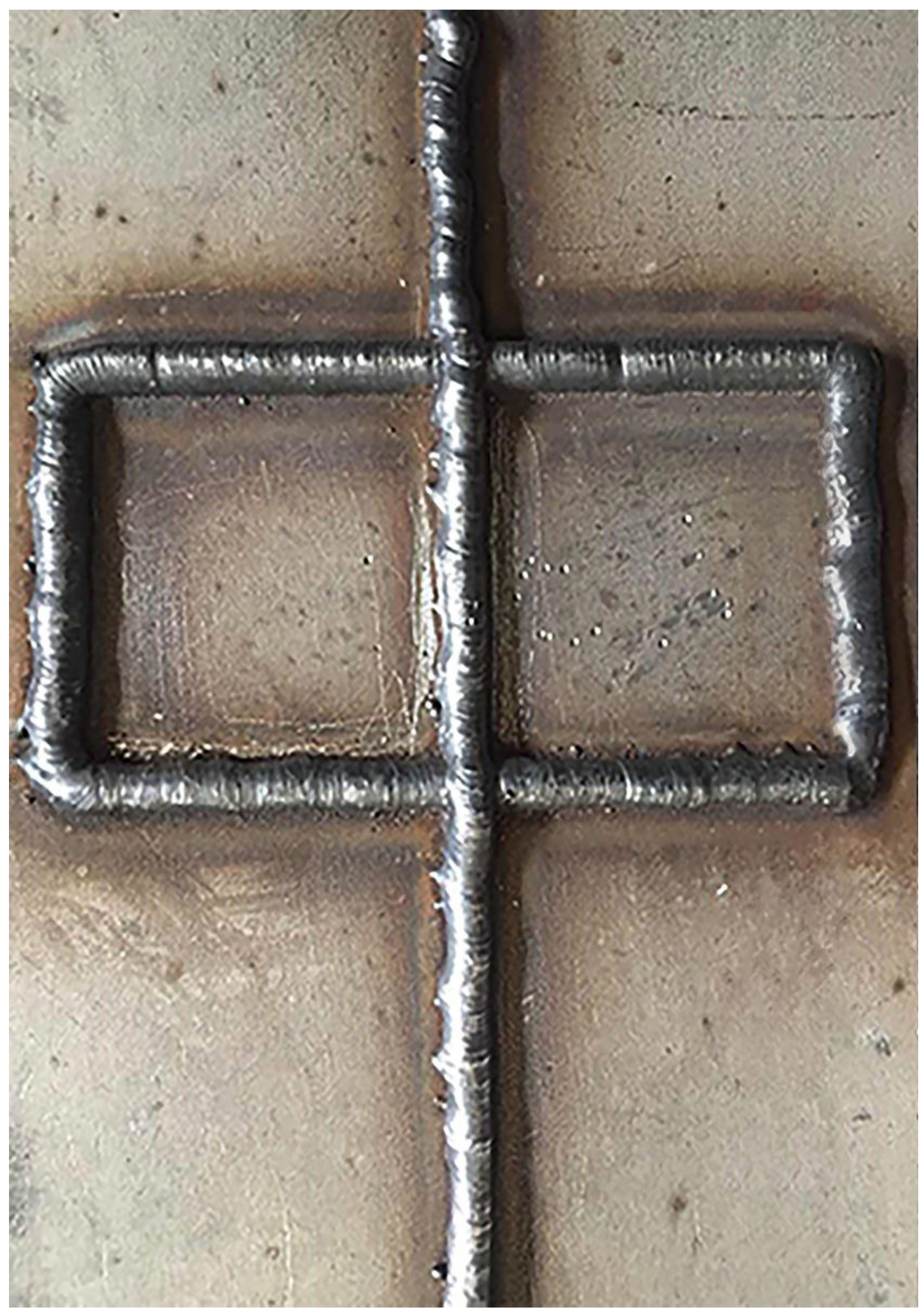

Figure 17

Metal part in form of Chinese character by self-adaptive DE-MPAW control system 


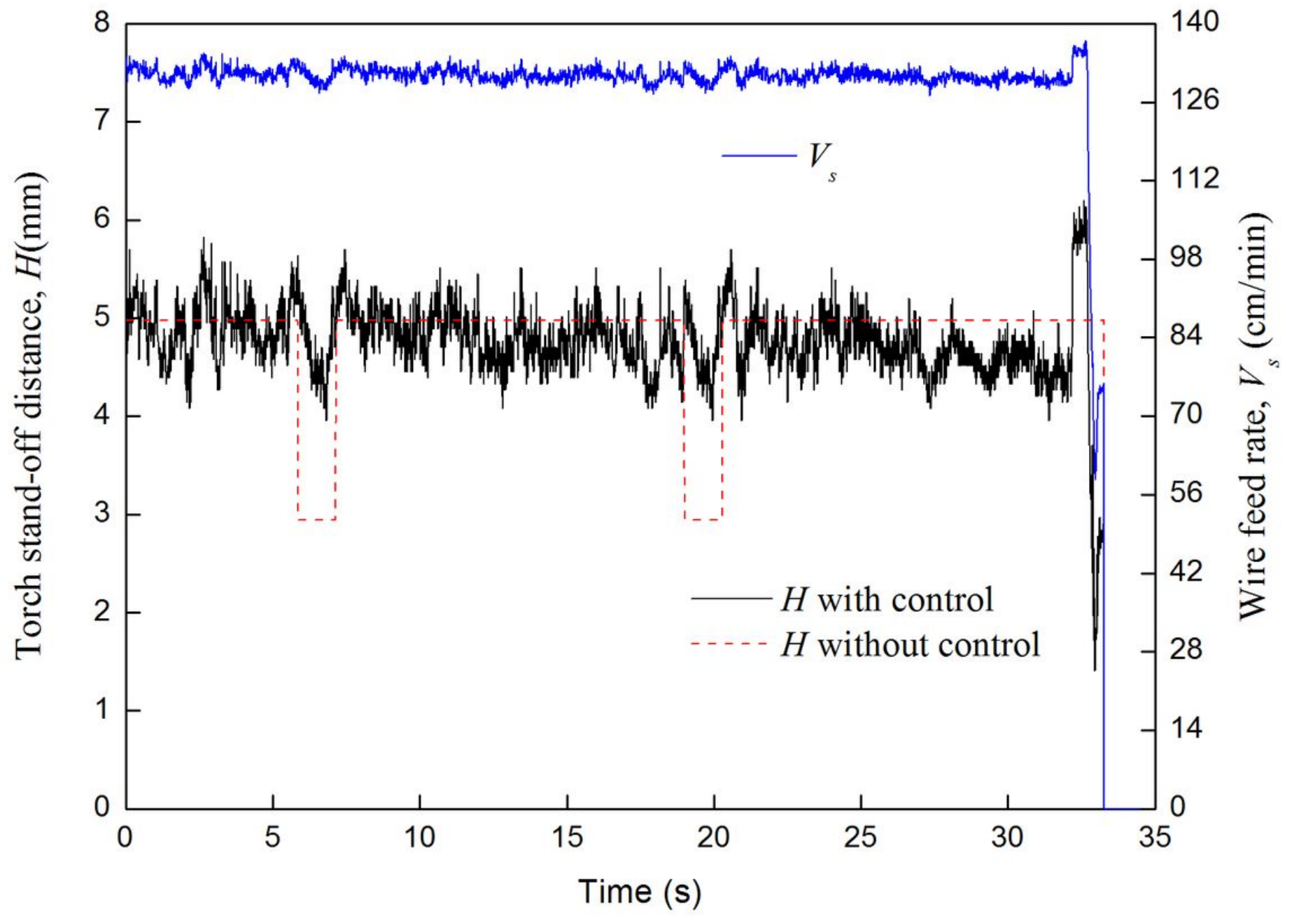

Figure 18

Voltage and wire feed rate for second deposition path. 


\section{Direction of deposition}
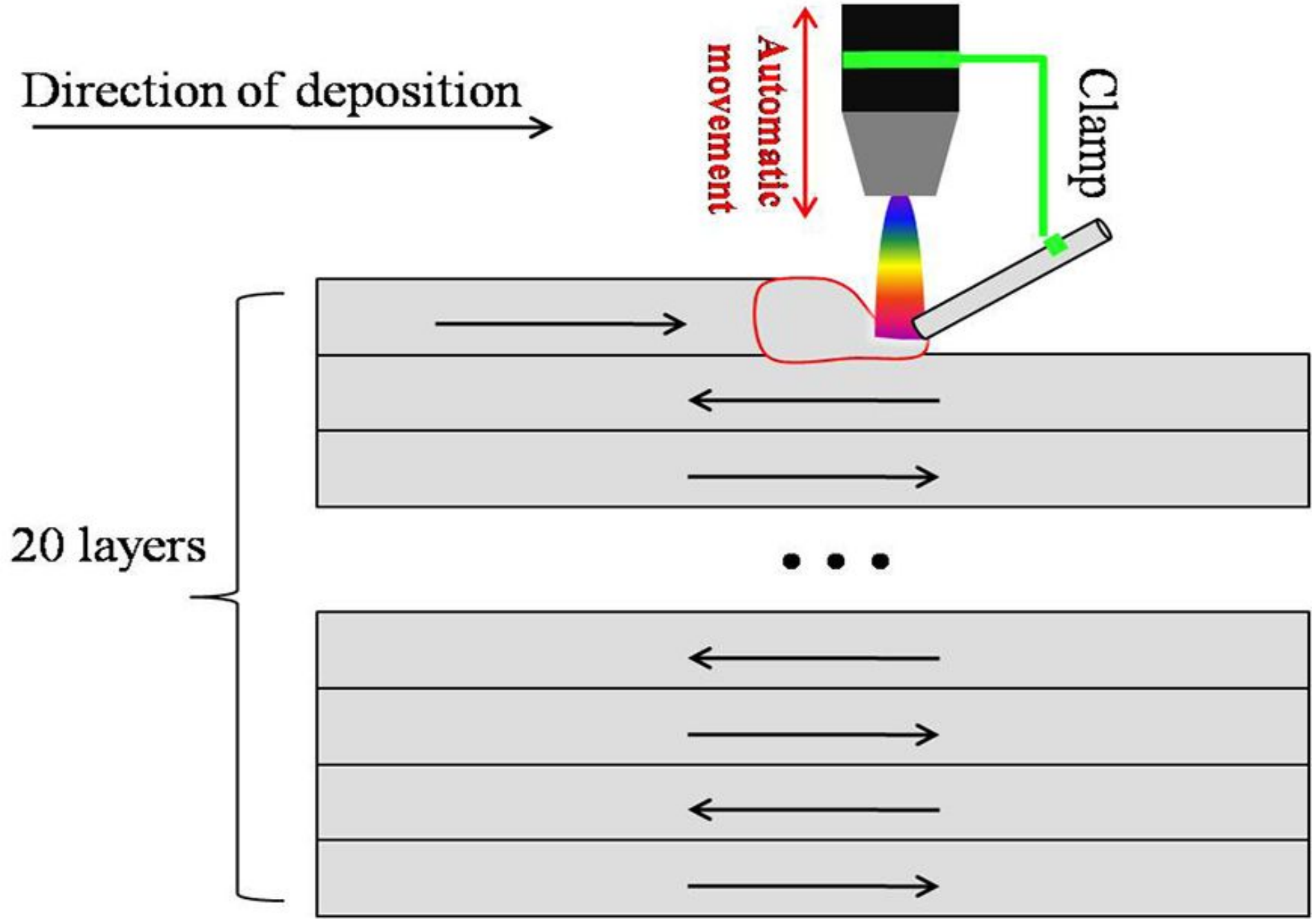

Figure 19

Schematic of deposition of single-walled component using proposed self-adaptive control system 


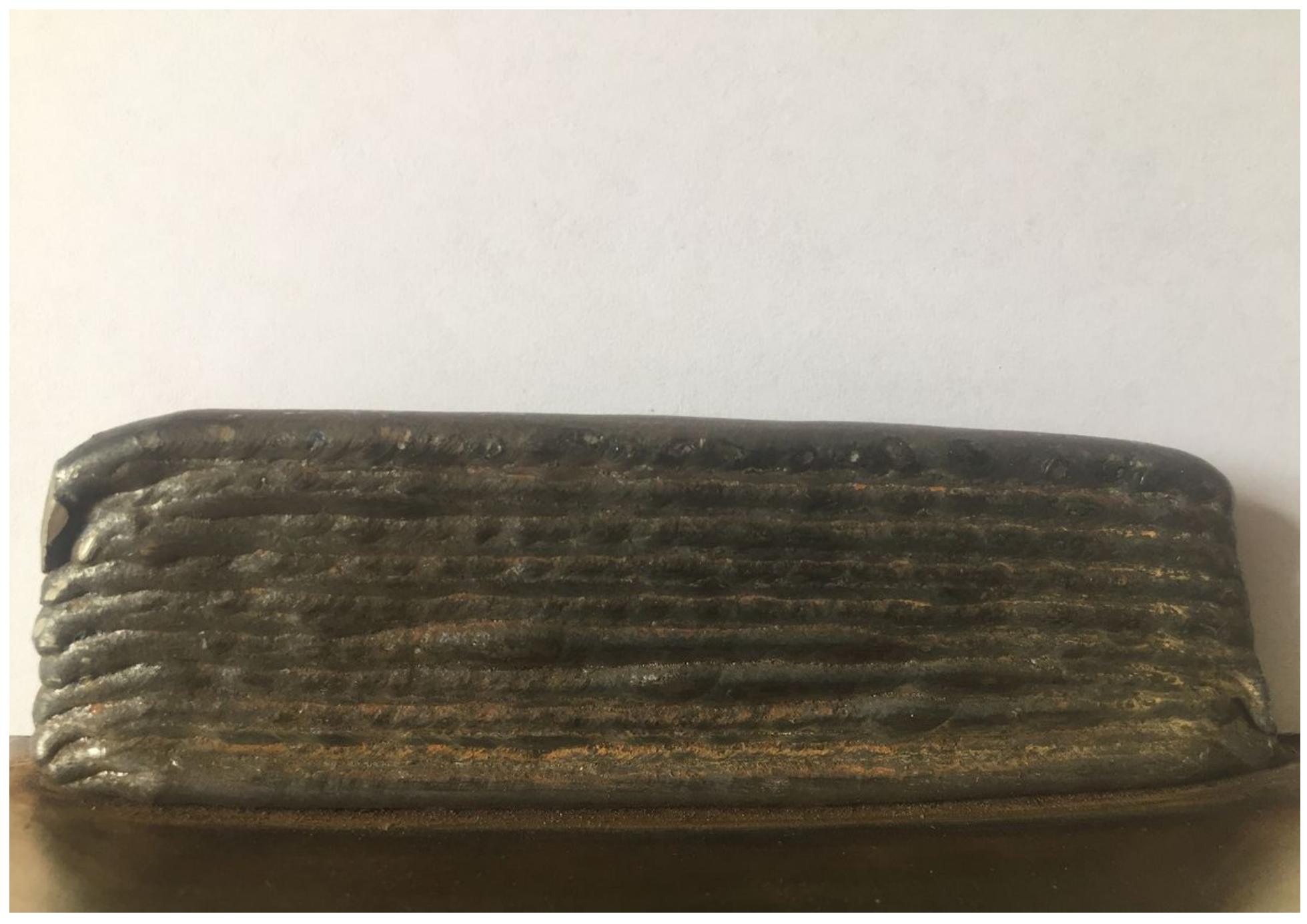

Figure 20

Single-walledcomponent deposited using proposed self-adaptive control system 


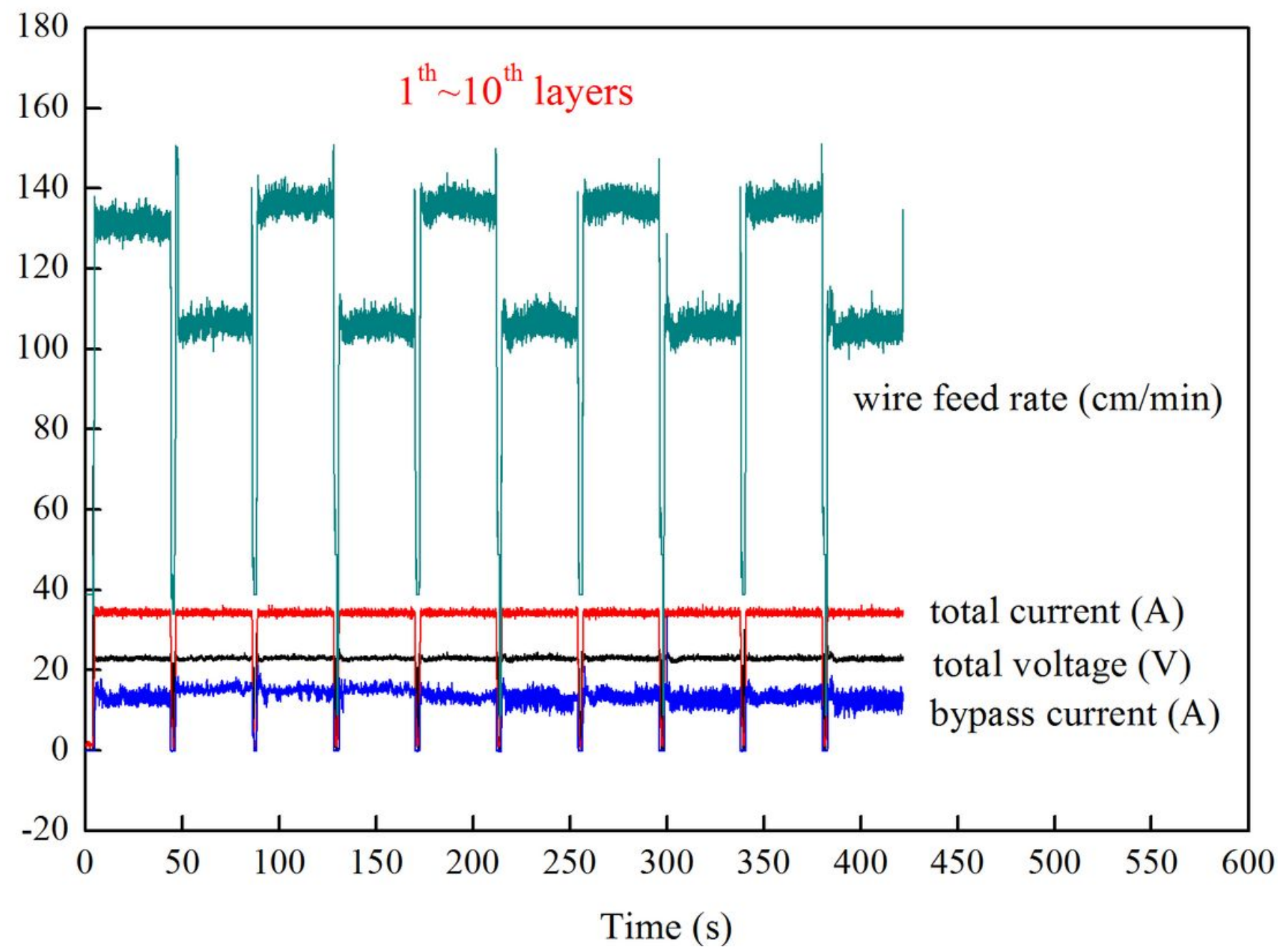

Figure 21

Parameters data collected in the deposition process of the 1 th $\sim 10$ th layers 


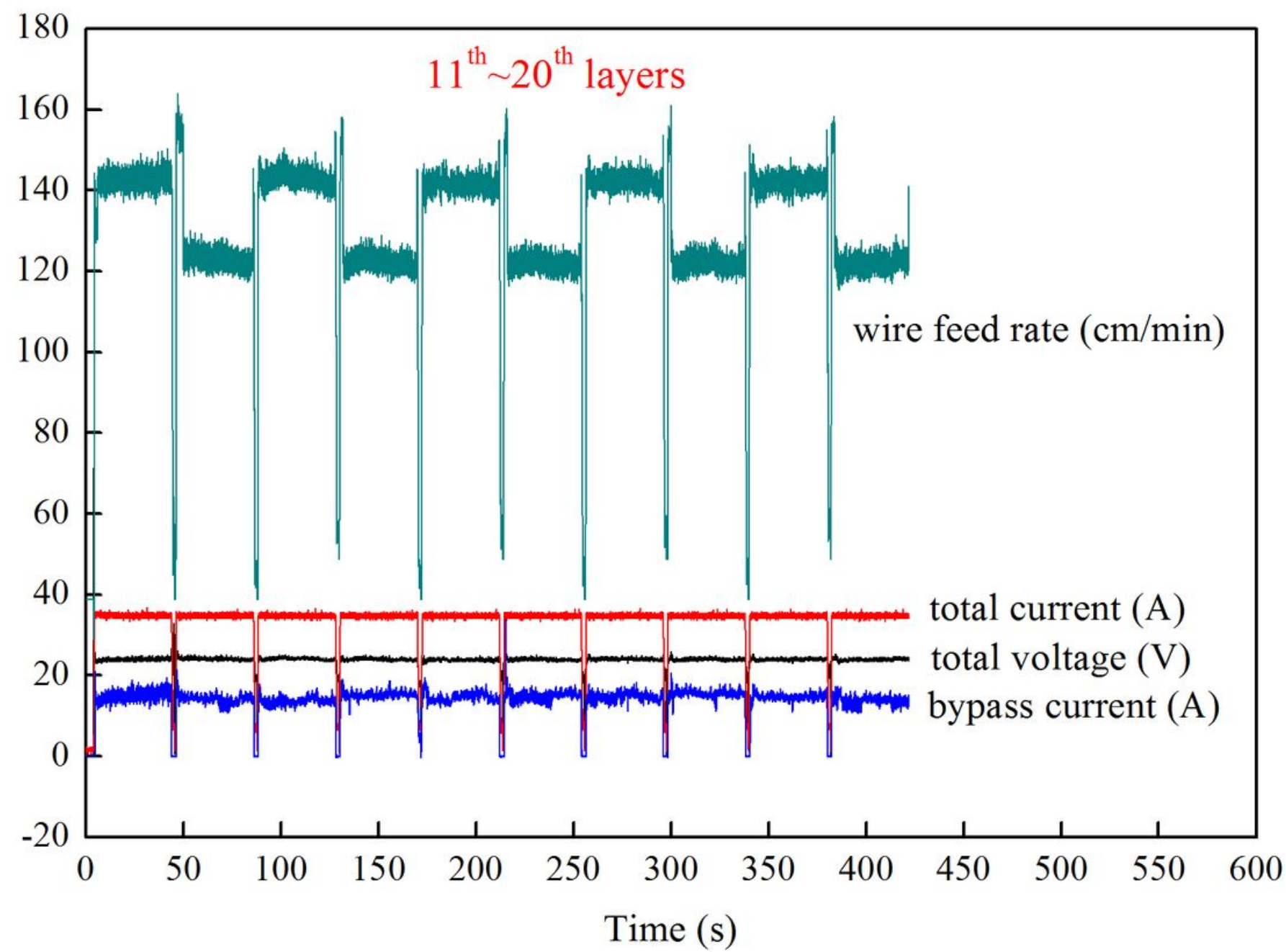

Figure 22

Parameters data collected in the deposition process of the 11 th $\sim 20$ th layers 